\title{
S100A3 a partner protein regulating the stability/activity of RARa and PML-RARa in cellular models of breast/lung cancer and acute myeloid leukemia
}

\author{
Maurizio Gianni ${ }^{1} \cdot$ Mineko Terao $^{1} \cdot$ Mami Kurosaki $^{1} \cdot$ Gabriela Paroni $^{1} \cdot$ Laura Brunelli $^{2} \cdot$ Roberta Pastorelli $^{2}$. \\ Adriana Zanetti ${ }^{1}$ - Monica Lupi ${ }^{3}$ - Andrea Acquavita ${ }^{1} \cdot$ Marco Bolis $^{1} \cdot$ Maddalena Fratelli $^{1} \cdot$ Cecile Rochette-Egly $^{4}$. \\ Enrico Garattini ${ }^{1}$
}

Received: 21 April 2018 / Revised: 1 August 2018 / Accepted: 20 October 2018 / Published online: 7 December 2018

(c) The Author(s) 2018. This article is published with open access, corrected publication 2022

\begin{abstract}
All trans-retinoic acid (ATRA) is used in the treatment of acute promyelocytic leukemia (APL) and it is a promising agent also in solid tumors. The pharmacological activity of ATRA is mediated by the ligand-activated RAR and RXR transcription factors. In the present study, we define the basal and ATRA dependent RAR $\alpha$ interactome in a RAR $\alpha$-overexpressing breast cancer cellular model, identifying 28 nuclear proteins. We focus our attention on the S100A3 calcium-binding protein, which interacts with RAR $\alpha$ constitutively. In ATRA-sensitive breast cancer cells, S100A3 binds to RAR $\alpha$ in basal conditions and binding is reduced by the retinoid. The interaction of S100A3 with RAR $\alpha$ is direct and in lung cancer, APL and acute-myeloid-leukemia (AML) cells. In APL, S100A3 interacts not only with RAR $\alpha$, but also with PML-RAR $\alpha$. The interaction surface maps to the RAR $\alpha$ ligand-binding domain, where the $I 396$ residue plays a crucial role. Binding of S100A3 to RAR $\alpha / P M L-R A R \alpha$ controls the constitutive and ATRA-dependent degradation of these receptors. S100A3 knockdown decreases the amounts of RAR $\alpha$ in breast- and lung cancer cells, inducing resistance to ATRA-dependent antiproliferative/differentiating effects. Conversely, S100A3 knockdown in PML-RAR $\alpha^{+}$APL and PML-RAR $\alpha^{-}$AML cells reduces the amounts of RAR $\alpha /$ PML-RAR $\alpha$ and increases basal and ATRA-induced differentiation. In this cellular context, opposite effects on RAR $\alpha /$ PML-RAR $\alpha$ levels and ATRA-induced differentiation are observed upon S100A3 overexpression. Our results provide new insights into the molecular mechanisms controlling RAR $\alpha$ activity and have practical implications, as S100A3 represents a novel target for rational drug combinations aimed at potentiating the activity of ATRA.
\end{abstract}

These authors contributed equally: Maurizio Gianni, Mineko Terao

Supplementary material The online version of this article (https:// doi.org/10.1038/s41388-018-0599-z) contains supplementary material, which is available to authorized users.

Enrico Garattini

enrico.garattini@marionegri.it

1 Laboratory of Molecular Biology, Istituto di Ricerche Farmacologiche Mario Negri IRCCS, via La Masa 19, 20156 Milano, Italy

2 Laboratory of Mass Spectrometry, Istituto di Ricerche Farmacologiche Mario Negri IRCCS, via La Masa 19, 20156 Milano, Italy

\section{Introduction}

All-trans retinoic acid (ATRA) is used in the treatment of acute promyelocytic leukemia (APL) [1, 2], which is characterized by a chromosomal translocation involving the retinoid-receptor, RAR $\alpha$, resulting in the production of the PML-RAR $\alpha$ oncogene [2-4]. ATRA is a promising agent in the treatment/chemoprevention of other neoplastic diseases, including breast cancer [3].

3 Laboratory of Cancer Pharmacology, Istituto di Ricerche Farmacologiche Mario Negri IRCCS, via La Masa 19, 20156 Milano, Italy

4 Department of Functional Genomics and Cancer, IGBMC (Institut de Génétique et de Biologie Moléculaire et Cellulaire), INSERM, U964; CNRS, UMR7104, Université de Strasbourg, 1 rue Laurent Fries, BP 10142, 67404 Illkirch Cedex, France 
ATRA activity is mediated by the ligand-activated transcription factors, $\operatorname{RAR} \alpha, \operatorname{RAR} \beta, \operatorname{RAR} \gamma, \operatorname{RXR} \alpha, \operatorname{RXR} \beta$, and $\operatorname{RXR} \gamma[4,5]$. These proteins consist of six regions $\mathrm{A}, \mathrm{B}, \mathrm{C}$, $\mathrm{D}, \mathrm{E}$, and $\mathrm{F}$ from the $\mathrm{N}$ - to the $\mathrm{C}$-terminus. The $\mathrm{C}$-region is involved in DNA-binding, while the E-region contains the ligand-binding pocket [6-9]. Transcriptionally active retinoid-receptors consist of RAR/RXR heterodimers, in which RARs acts as the ligand-binding moiety. Unliganded RAR/RXR heterodimers bind to RAREs (retinoic-acidresponsive-elements) located in the regulatory regions of retinoid target-genes [6, 10]. Ligand-free RAR/RXR heterodimers are part of multi-protein complexes whose composition is modified upon ligand-binding. Specific RARs and RXRs interact with different proteins which modulate their transcriptional activity, phosphorylation/dephosphorylation [11], degradation [12] and subcellular localization [13].

Here, we use a proteomic approach to identify novel proteins interacting with $\operatorname{RAR} \alpha$. Among the proteins showing a strong interaction with $\operatorname{RAR} \alpha$, we focus on the calcium-binding protein, S100A3. The interaction of $\mathrm{S} 100 \mathrm{~A} 3$ with $\mathrm{RAR} \alpha$ is observed in breast cancer and lung cancer, acute-myeloid-leukemia (AML) as well as acute promyelocytic leukemia (APL) cells, in which S100A3 binds also to PML-RAR $\alpha$. S100A3 binding controls constitutive and ATRA-dependent degradation of RAR $\alpha$ and PML-RAR $\alpha$. This interaction has opposite consequences on the anti-proliferative and differentiating activity of ATRA in breast cancer and lung cancer relative to AML and APL cells.

\section{Results}

\section{Identification of RARa interacting proteins}

$\operatorname{RAR} \alpha$ is the major determinant of ATRA anti-tumor activity in breast cancer $[3,5]$. To identify novel RAR $\alpha$ interacting proteins, we stably transfected a FLAG-tagged RAR $\alpha$ (FLAG-RAR $\alpha$ ) plasmid and the corresponding void vector in ATRA-resistant $M D A-M B-453$ breast cancer cells [3, 14], generating $R A-453$ and $F L-453$ cells, respectively. In basal conditions, $R A-453$ express higher levels of $\operatorname{RAR} \alpha$ than parental $M D A-M B-453$ and $F L-453$ cells (Supplementary Fig. 1A). Unlike $M D A-M B-453$ and $F L-453, R A-453$ cells are responsive to the transcriptional and growth-inhibitory effects of ATRA. In fact, $R A-453$ cells transfected with a retinoid-dependent luciferase reporter (DR5-RARELuc) show stimulation of luciferase activity by ATRA. In addition, $R A-453$ growth is reduced by ATRA in a dosedependent manner (Supplementary Fig. 1B).

To screen for RAR $\alpha$-binding proteins in $R A-453$ and $F L-453$ cells, we used a quantitative proteomic approach
[15, 16] (Supplementary Fig. 2). Nuclear fractions enriched for DNA-binding (NABP, nucleic acid binding proteins) and histonic (INP, insoluble nuclear proteins) proteins were extracted from $R A-453$ and $F L-453$ cells exposed to vehicle or ATRA. Each nuclear fraction was immunoprecipitated with anti-FLAG antibodies and subjected to proteomic analysis. Twenty-eight of the proteins identified are present only in the $R A-453$ immunoprecipitates (Supplementary Table 1 and Supplementary Table 2). Ten proteins bind to unliganded $\operatorname{RAR} \alpha$ and binding is increased by at least 1.5fold following treatment with ATRA (Supplementary Table 1). With the exception of CEP83 [17] and RL1D1 [18], all these interactors are histone proteins. Interestingly, CEP83 and RL1D1 are contained in the INP fraction. Thus, RAR $\alpha$ binding of these proteins may be indirect and mediated by one of the identified histones. The H2AW core-histone protein shows maximal ATRA-dependent stimulation of RAR $\alpha$-binding.

Seventeen proteins, none of which is a histone, are identifiable in the $N A B P$ and INP fractions of vehicletreated RA-453 cells (Supplementary Table 2). RAR $\alpha-$ binding of all these proteins is reduced by ATRA.

\section{S100A3, FABP5, and HSPB1 bind to unliganded RARa and the interaction is diminished by ATRA}

We focused on the three RAR $\alpha$ interactors, S100A3, FABP5, and HSPB1. S100A3 is a calcium-binding protein involved in transcription [19-21]. FABP5 protein binds and delivers ATRA to the PPAR $\beta / \delta$ nuclear-receptor [22-24]. HSPB1/HSP27 is a heat-shock protein whose expression is modulated by ATRA [25-27]. Detectable levels of FABP5, HSPB1/HSP27 (Supplementary Fig. 3A and Supplementary Fig. 3B), and S100A3 (Fig. 1a) are observed in vehicle and ATRA-treated $F L-453$ as well as $R A-453$ cells. ATRA treatment does not alter the basal expression of the three proteins.

We validated the observed interactions of S100A3, FABP5, and HSPB1/HSP27 with RAR $\alpha$ using coimmunoprecipitation studies (Fig. 1a and Supplementary Fig. 3A, B). Anti-FLAG antibodies immunoprecipitate RAR $\alpha$ only in $R A-453$ cells and the amount of immunoprecipitated RAR $\alpha$ is similar in vehicle- and ATRA-treated $R A-453$ cells. In $R A-453$ cells, S100A3 (Fig. 1a), FABP5 (Supplementary Fig. 3A), and HSPB1/HSP27 (Supplementary Fig. 3B) co-immunoprecipate with RAR $\alpha$ and the levels of the three co-immunoprecipitated proteins are higher with vehicle than ATRA. This confirms the proteomic results and indicates that S100A3, FABP5, and HSPB1/HSP27 interact predominantly with unliganded RAR $\alpha$. The interaction of S100A3, FABP5, and HSPB1/ HSP27 with RAR $\alpha$ in $R A-453$ cells is also observed if the anti-FLAG immunoprecipitating antibodies are substituted 


\section{S100A3}
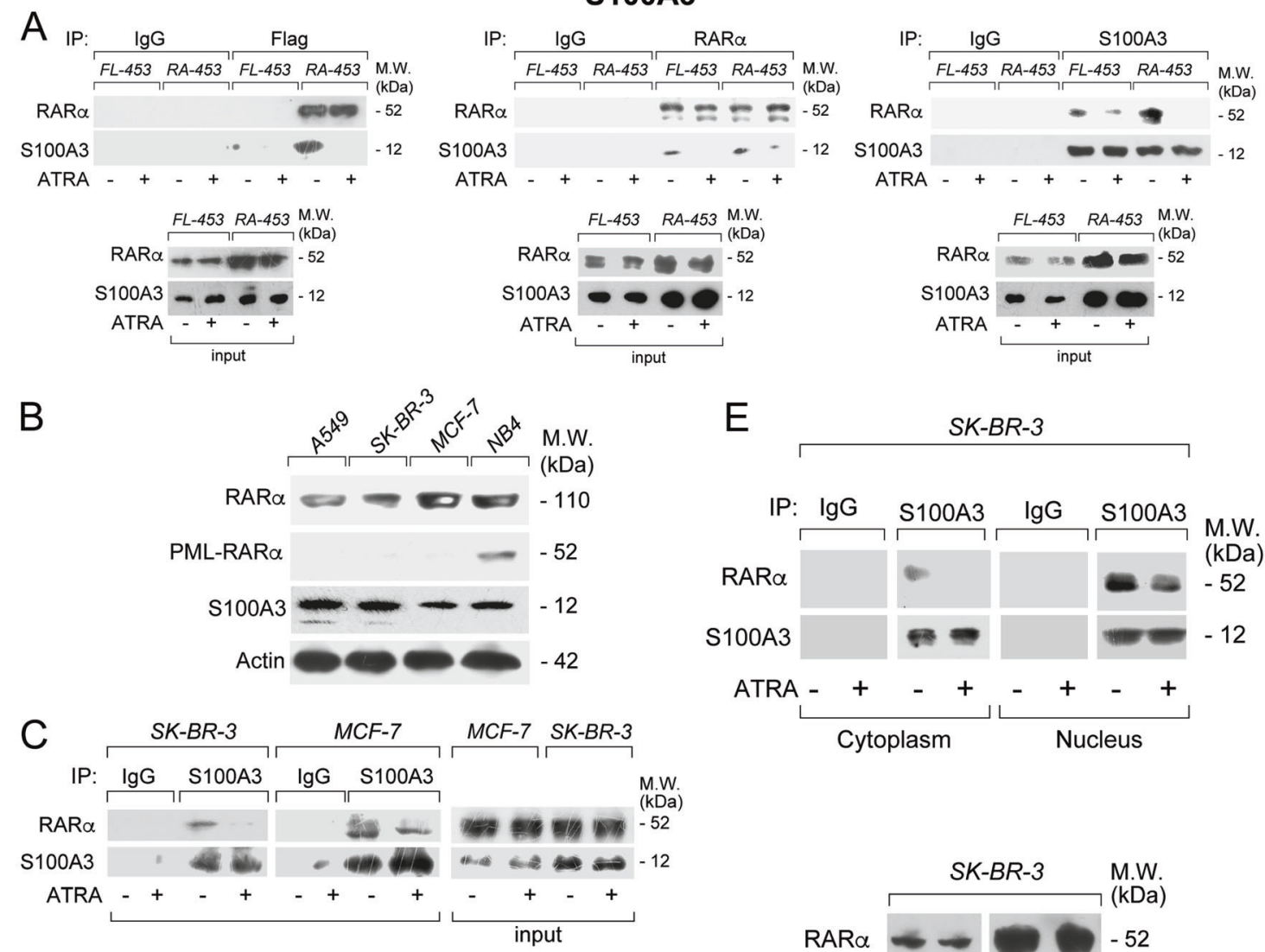

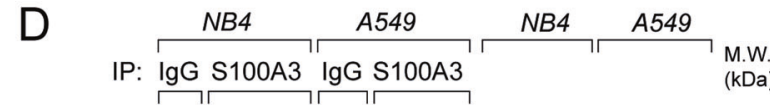
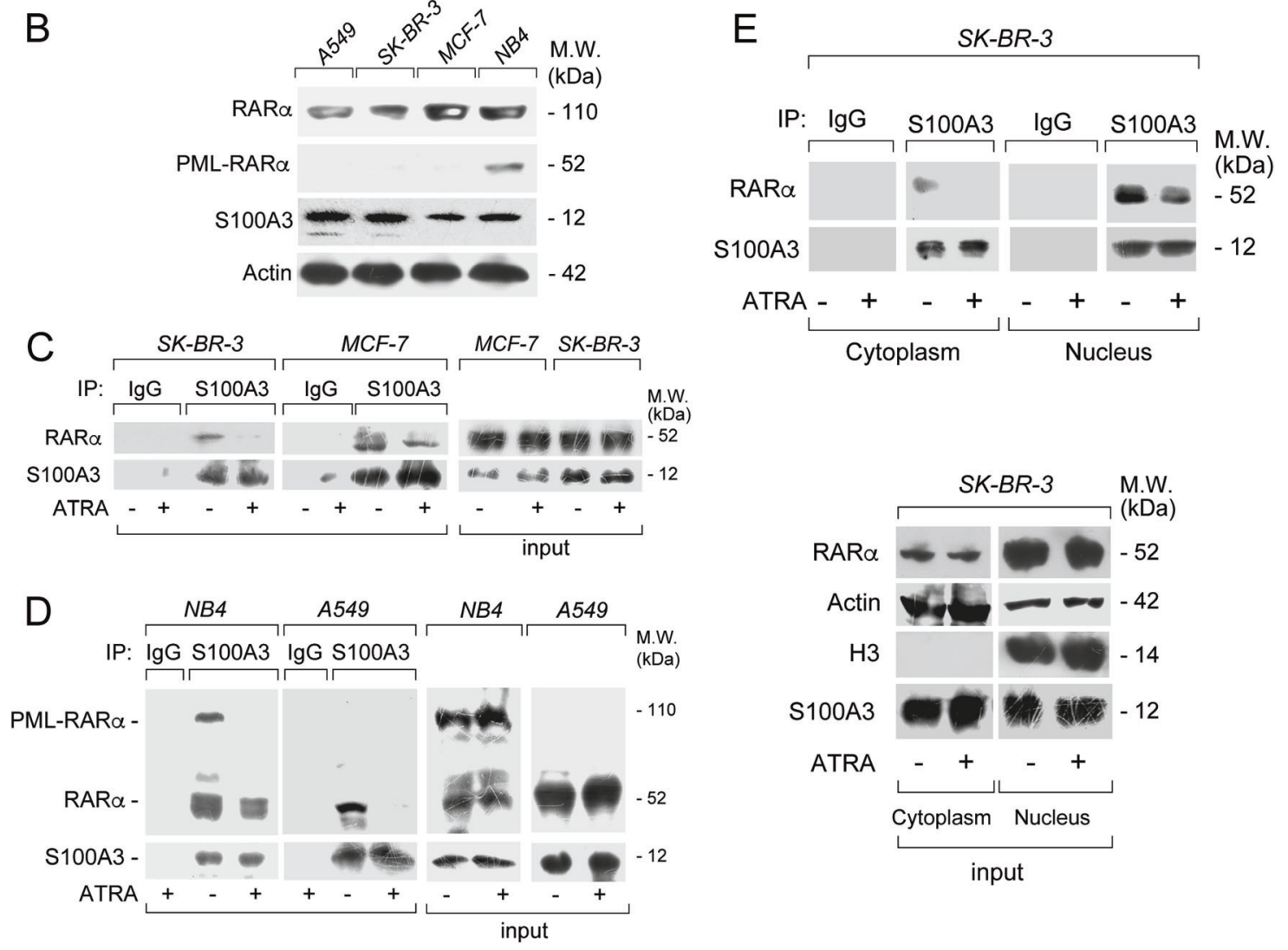

$\mathrm{F}$
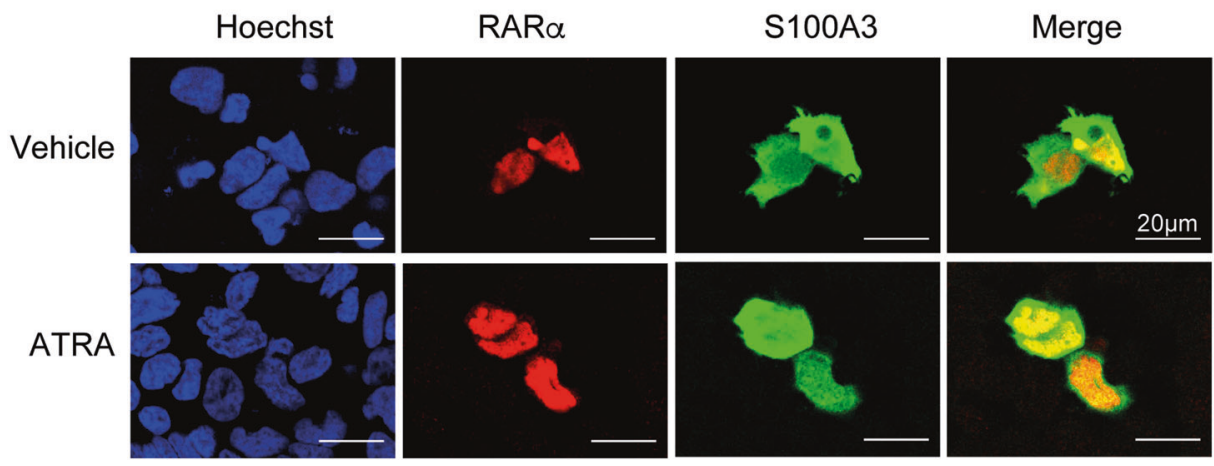

by anti-RAR $\alpha$ antibodies. Noticeably, anti-RAR $\alpha$ antibodies immunoprecipitate not only FLAG-tagged RAR $\alpha$, but also endogenous RAR $\alpha$, which is expressed in both $R A-453$ and $F L-453$ cells, albeit at low levels. Further evidence supporting specific interactions between RAR $\alpha$ and these proteins comes from the co-immunoprecipitation studies with anti-FABP5, anti-HSPB1 or anti-S100A3 antibodies. 
Fig. 1 Interactions between S100A3 and RAR $\alpha$ in breast cancer $F L$ 453, RA-453, SK-BR-3, and MCF7 cells, lung cancer $A 549$ cells as well as APL-derived NB4 cells. a $F L-453$ and $R A-453$ cells were treated with vehicle (DMSO) or ATRA $(1 \mu \mathrm{M})$ for $1 \mathrm{~h}$. At the end of the treatment, total cell extracts were immunoprecipitated with antiFLAG mouse monoclonal antibodies (left), anti-RAR $\alpha$ mouse monoclonal antibody (middle), and anti-S100A3 mouse monoclonal antibodies (right) or the corresponding non-specific immuno-globulins $\mathrm{G}$ (IgG) as negative controls. Following normalization for the content of $\mathrm{RAR} \alpha$ or S100A3 in the input, the various immunoprecipitates were subjected to western blot analysis with an anti-RAR $\alpha$ rabbit polyclonal antibody or the anti-S100A3 antibody, as indicated. M.W. = molecular weights of the indicated proteins. Input $=$ western blot analysis of the cell extracts before the indicated immunoprecipitation step. Each immunoprecipitation is representative of at least two independent experiments providing the same type of results. b Extracts from logarithmically growing breast cancer $S K-B R-3$ and $M C F 7$ cells, lung cancer $A 549$ cells as well as APL-derived NB4 cells were subjected to western blot analysis with antibodies targeting RAR $\alpha$ and PMLRAR $\alpha$, S100A3, and $\beta$-actin. The molecular weights of the indicated proteins are shown on the right. $S K-B R-3$ and $M C F 7$ (c) as well as $N B 4$ and $A 549(\mathbf{d})$ cells were treated with vehicle (DMSO) or ATRA $(1 \mu \mathrm{M})$ for $1 \mathrm{~h}$. At the end of the treatment, total cell extracts were immunoprecipitated with anti-S100A3 mouse monoclonal antibodies (IP: S100A3). The negative control for the immunoprecipitations is represented by the extracts challenged with non-specific immunoglobulins $\mathrm{G}$ (IP: $\mathrm{IgG}$ ), as indicated. Following normalization for the content of S100A3 in the input, the immunoprecipitates were subjected to western blot analysis with anti-RAR $\alpha$ and anti-S100A3 antibodies, as indicated. Input $=$ western blot analyses of the cell extracts before the immunoprecipitation step. M.W. = molecular weights of the indicated proteins. e $S K-B R-3$ cells were treated with vehicle (DMSO) or ATRA $(1 \mu \mathrm{M})$ for $1 \mathrm{~h}$. At the end of the treatment, the nuclear (Nucleus) and the cytoplasmic (Cytoplasm) fractions of the cells were separated by centrifugation and subjected to immunoprecipitation with the anti-S100A3 antibody or the control IgG. As in (c), the immunoprecipitates were subjected to western blot analysis with anti-RAR $\alpha$ and anti-S100A3 antibodies. Input $=$ western blot analyses of the cell extracts before the immunoprecipitation step. The input data obtained with the nuclear marker, Histone $\mathrm{H} 3(\mathrm{H} 3)$, demonstrate efficient separation of the nuclear from the cytoplasmic fractions. Each immunoprecipitation is representative of at least two independent experiments providing the same type of results. f $M D A-M B-453$ cells were co-transfected with RAR $\alpha$ and S100A3 expression plasmids. Twenty-four hours following transfection, cells were challenged with primary anti-RAR $\alpha$ rabbit polyclonal antibodies mouse and antiS100A3 monoclonal antibodies. Subsequently the cell slides were labeled with red-fluorescent anti-rabbit-Ig and green fluorescent antimouse-Ig secondary antibodies. Cell nuclei are shown in blue following staining with the Hoechst dye. Merging of the red- and greenfluorescence images is shown in the rightmost panels

\section{$\mathrm{RARa} / \mathrm{S} 100 \mathrm{A3}$ interaction is a general phenomenon and it occurs in the nucleus}

We concentrated on S100A3, as the relevance of this protein for the biological activity of ATRA is unknown. To evaluate whether S100A3/RAR $\alpha$ interaction is a general phenomenon, we performed co-immunoprecipitation studies in ATRA-sensitive tumor cell lines of different origin. We considered breast cancer $S K-B R-3$ and $M C F-7$ cells [3], lung cancer A-549 cells [28] as well as APL-derived and PML-RAR $\alpha^{+} N B 4$ blasts $[29,30]$ which synthesize measurable levels of S100A3 and RAR $\alpha$ (Fig. 1b). RAR $\alpha$ and S100A3 are detectable in the anti-S100A3 immunoprecipitates of vehicle-treated $S K-B R-3, M C F-7, A-549$, and $N B 4$ cells (Fig. 1c, d). ATRA reduces the amounts of coimmunoprecipitated RAR $\alpha$, regardless of the cell line considered. In NB4 cells, S100A3 interacts also with PMLRAR and the interaction is reduced by ATRA (Fig. 1d).

We evaluated the subcellular distribution of the RAR $\alpha /$ S100A3 interaction in $S K-B R-3$ cells, using quantitative immunoprecipitation, following separation of the nuclear and cytoplasmic fractions (Fig. 1e). As expected, RAR $\alpha$ localizes predominantly to the nucleus [31-33], while S100A3 is evenly distributed in the cytosol and the nucleus (Fig. 1e-input). In basal conditions, the anti-S100A3 antibody co-immunoprecipitates significant amounts of RAR $\alpha$ only from the nucleus and RAR $\alpha$ nuclear protein levels are reduced by ATRA. Immunofluorescence experiments performed in $M D A-M B-453$ cells transiently transfected with RAR $\alpha$ and S100A3 support these results (Fig. 1f), demonstrating punctuate co-localization of RAR $\alpha$ and S100A3 only inside the nucleus.

\section{S100A3 interacts with RARa, PML-RARa, and RARY}

To validate the observation that S100A3 interacts with RAR $\alpha / P M L-R A R \alpha$ and to evaluate whether the calciumbinding protein recognizes other members of the RAR/RXR family, we used the COS-7 cellular model [31]. We performed co-immunoprecipitation experiments following overexpression of S100A3 with RAR $\alpha$, PML-RAR $\alpha$, RAR $\beta$, RAR $\gamma$, or RXR $\alpha$ (Fig. 2a). RAR $\alpha$ and PML-RAR $\alpha$ are not the only S100A3-interacting retinoid-receptors, as anti-S100A3 antibodies co-immunoprecipitate also RAR $\gamma$. As expected, binding of RAR $\alpha$, PML-RAR $\alpha$, and RAR $\gamma$ to S100A3 is reduced by ATRA. To confirm these results, we performed GST pull-down assays [32] in COS-7 cells overexpressing RAR $\alpha$, RAR $\beta$, RAR $\gamma$, and $\operatorname{RXR} \alpha$. In basal conditions, only RAR $\alpha$ and RAR $\gamma$ are specifically pulled down by GST-tagged S100A3 (GST-S100A3, Fig. 2b).

\section{Definition of the RARa structural determinants of the interaction with S100A3}

To get insights into the structural determinants of the RAR $\alpha / S 100 A 3$ interaction, we performed GST pull-down assays using deletion-/phosphorylation-mutants of the retinoid-receptor. We over-expressed the following RAR $\alpha$ deletion-mutants in $C O S-7$ cells: $\triangle A B$, deleted for the A/Bregions; $\Delta H 12(408-416)$, deleted for the H12-helix in the ligand-binding E-region; $\Delta 403-462$, deleted for a portion of the $\mathrm{E}$ - and the entire F-region; $\Delta F$, deleted for the F-region 


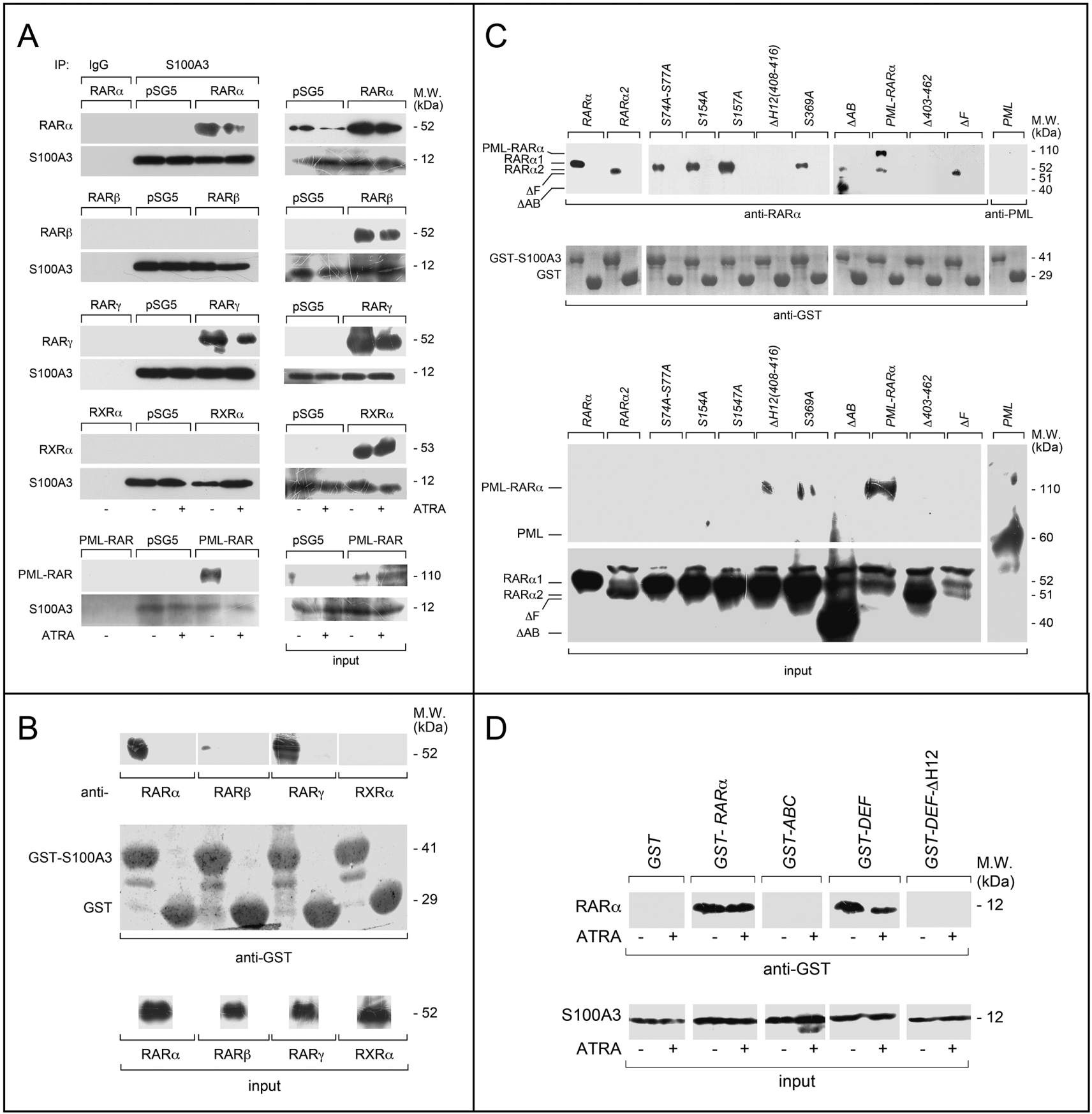

[9, 33]; $\Delta C$, deleted for the DNA-binding C-region; $\Delta D$, deleted for the D-hinge-region (Supplementary Fig. 4). In addition, we over-expressed PML-RAR $\alpha$ and the RAR $\alpha 2$ splicing-variant [32] and used $P M L$ as an internal control. Only $\Delta H 12(408-416)$ and $\Delta 403-462$ lose the ability to interact with S100A3 (Fig. 2c). Deletion of the C- and Dregions causes a major reduction of the S100A3-interaction, although it does not abrogate binding (Supplementary Fig. $5)$. This last observation must be taken with caution as the absence of the C- or D-regions has major effects on the tridimensional structure of the RAR protein. Thus, the GST pull-down experiments confirm that PML-RAR $\alpha$ interacts with S100A3. This interaction is due to the RAR $\alpha$ moiety, as PML is not recognized by GST-S100A3.

$\operatorname{RAR} \alpha$ is phosphorylated at different residues in basal conditions or following exposure to ATRA [11]. Specific phosphorylation sites control the levels and functional activity of the retinoid-receptor. To evaluate whether some of the known phosphorylation sites play a role in the S100A3/RAR $\alpha$ interaction, we performed GST pull-down studies with available Ser/Ala phosphorylation-mutants. We used the following phosphorylation-mutants: $S 74 A-S 77 A$, inactivating two p38 and CDK dependent phosphorylation sites of the B-domain [34, 35]; S154A and S157A, 
Fig. 2 Specificity and structural determinants of RAR $\alpha$ binding to S100A3. a COS-7 cells were co-transfected with equal amounts of RAR $\alpha$, PML-RAR $\alpha$, RAR $\beta$, RAR $\gamma$ or RXR $\alpha$, and S100A3 expression plasmids, as indicated. The negative control for the experiments is represented by cells co-transfected with the void expression plasmid (pSG5). Twenty-four hours following transfection, cells were treated with vehicle (DMSO) or ATRA $(1 \mu \mathrm{M})$ for $1 \mathrm{~h}$. At the end of the treatment, total cell extracts were immunoprecipitated with antiS100A3 mouse monoclonal antibodies (IP: S100A3). A further negative control for the immunoprecipitations is represented by the extracts of COS-7 cells co-transfected with pSG5 and the S100A3 expression plasmid which were challenged with non-specific immunoglobulins G (IP: IgG). Following normalization for the content of S100A3 in the input, the various immunoprecipitates were subjected to western blot analysis with anti-RAR $\alpha$, anti-RAR $\beta$, anti-RAR $\gamma$, or antiRXR $\alpha$ antibodies. All the blots were subsequently re-challenged with anti-S100A3 antibodies, as indicated. Input = western blot analysis of the cell extracts before the indicated immunoprecipitation step. Each immunoprecipitation is representative of at least two independent experiments providing the same type of results. b, $\mathbf{c}$ GST pull-down: the GST-tagged recombinant protein, GST-S100A3, and the GST negative control were used. The two recombinant proteins conjugated to Glutathione-Sepharose beads were incubated with extracts of $C O S-7$ cells transfected with the $p S G 5$ expression plasmids containing wildtype RAR $\alpha, \operatorname{RAR} \beta, \operatorname{RAR} \gamma, \operatorname{RXR} \alpha, \operatorname{RAR} \alpha 2$, PML-RAR $\alpha$ and the indicated RAR $\alpha$ deletion-mutants and point-mutants. GST pull-down precipitates were blotted on nitro-cellulose filters, incubated with an anti-RAR $\alpha$, anti-RAR $\beta$, anti-RAR $\gamma$, anti-RXR $\alpha$ antibodies (b) or antiRAR $\alpha$ antibodies only (c). Subsequently the filters were re-blotted with an anti-GST antibody, as indicated. Input: cell extracts $(15 \mu \mathrm{g}$ of protein) representing $10 \%$ of the total amount of protein were subjected to western blot analysis with the above anti-RAR $\alpha$ antibody. d Far-western: COS-7 cells were transfected with the same S100A3 expression plasmid as in (a). Cell extracts were precipitated with sepharose beads conjugated with an anti-S100A3 monoclonal antibody. The immunoprecipitates were subjected to far-western analysis using the following GST-tagged RAR $\alpha$ recombinant proteins: GST$R A R \alpha=$ full-length RAR $\alpha ; G S T-A B C=\mathrm{RAR} \alpha \mathrm{ABC}$ regions; $G S T$ $D E F=\mathrm{RAR} \alpha \mathrm{DEF}$ regions; GST-DEF $\Delta H 12=\mathrm{RAR} \alpha 1 \mathrm{DEF}$ regions lacking the H12-helix. The blots were developed with an anti-GST antibody. Input: cell extracts ( $15 \mu \mathrm{g}$ of protein) representing $10 \%$ of the total amount of protein used for the immunoprecipitations were subjected to western blot analysis with an anti-S100A3 antibody. Each line shows cropped lanes of the same gel, hence the results can be compared across the lanes, as they were obtained with the same exposure time. M.W. = molecular weights of the indicated proteins

inactivating the PKC-dependent phosphorylation sites of the C-domain [36]; S369A, inactivating a PKA/p38-dependent phosphorylation site in the E-domain [37] (Supplementary Fig. 4). None of the four phosphorylation mutant exerts a significant effect on the interaction with S100A3 (Fig. 2c). As ATRA activates the phosphorylation of all these mutated Ser-residues [11], the amino-acids are also unlikely to be involved in the diminution of RAR $\alpha / S 100 A 3$ interaction caused by the retinoid (see also Fig. 3a, $S 74 A$ S77A).

To establish whether the interaction between S100A3 and RAR $\alpha$ is direct, far-western experiments [32] were performed in COS-7 cells over-expressing S100A3 (Fig. $2 \mathrm{~d})$. The results demonstrate that GST-RAR $\alpha$ interacts with
S100A3. The interaction is reproduced with the GST-RAR $\alpha$ derivative consisting of the DEF regions (GST-DEF) [32], but not with similar proteins consisting of the $A B C$-regions $(G S T-A B C)$ or the DEF regions lacking the H12-helix (GST-DEFAH12). This demonstrates that S100A3 interacts with RAR $\alpha$ in a direct manner and confirms the importance of the H12-helix in the interaction.

\section{S100A3 controls the transcriptional activity and the degradation of RARa and PML-RARa}

To evaluate whether the interaction with S100A3 exerts any effect on the transcriptional activity and the levels of the two retinoid-receptors, we co-transfected $\mathrm{COS}-7$ cells with S100A3 and RAR $\alpha$ or PML-RAR $\alpha$ in the presence of a retinoid-dependent luciferase reporter. S100A3 reduces ATRA-dependent stimulation of RAR $\alpha$ and PML-RAR $\alpha$, as assessed by the luciferase reporter (Fig. 3a). In vehicletreated COS-7 cells, S100A3 upregulates both RAR $\alpha$ and PML-RAR $\alpha$ proteins. In the absence of S100A3, ATRA reduces the amounts of the two receptor proteins [12, 32], a phenomenon which is not observed in S100A3 overexpressing cells. The effects exerted by S100A3 on the levels of RAR $\alpha$ and PML-RAR $\alpha$ proteins are translational/ posttranslational, as they are not accompanied by alterations in the amounts of the corresponding mRNAs (data not shown). The data suggest that S100A3 increases the levels of a transcriptionally-inactive form of RAR $\alpha$ and PMLRAR $\alpha$. The specificity of the results is confirmed with the use of PML as a negative control.

To support the idea that the results obtained are due to the S100A3-interaction, we performed similar experiments with RAR $\alpha 2$, RAR $\beta, \operatorname{RAR} \gamma$, and RAR $\alpha$ deletion- or pointmutants maintaining $(\triangle A B$ and $S 74 A-S 77 A)$ or losing $(\triangle H 12$ (408-416) and $\Delta 403-462$ ) the ability to bind S100A3 (Fig. 3a). S100A3 increases the protein levels and inhibits the ATRA-dependent luciferase activity of RAR $\alpha 2, \operatorname{RAR} \gamma$, $\triangle A B$, and $S 74 A-S 77 A$. In contrast, the amounts of RAR $\beta$, $\triangle H 12(408-416)$, and $\Delta 403-462$ proteins are not modified by $\mathrm{S} 100 \mathrm{~A} 3$ overexpression. In the case of RAR $\beta$ protein, S100A3 has also no influence on ATRA-dependent luciferase activity.

To determine the effects of S100A3 on the stability of the two proteins, COS-7 cells were transfected with S100A3 and RAR $\alpha$ or PML-RAR $\alpha$ before exposure to cycloheximide for different amounts of time in the absence (Fig. 3b) and presence of ATRA (Fig. 3c). In basal conditions, S100A3 increases the stability of RAR $\alpha$ and PML-RAR $\alpha$ (Fig. 3b, lower graphs). By the same token, S100A3 reduces ATRA-dependent degradation of the two retinoidreceptors, a phenomenon associated with ligand-dependent transcriptional activation [29]. As the proteasome is involved in the degradation of the two receptors [38], we 

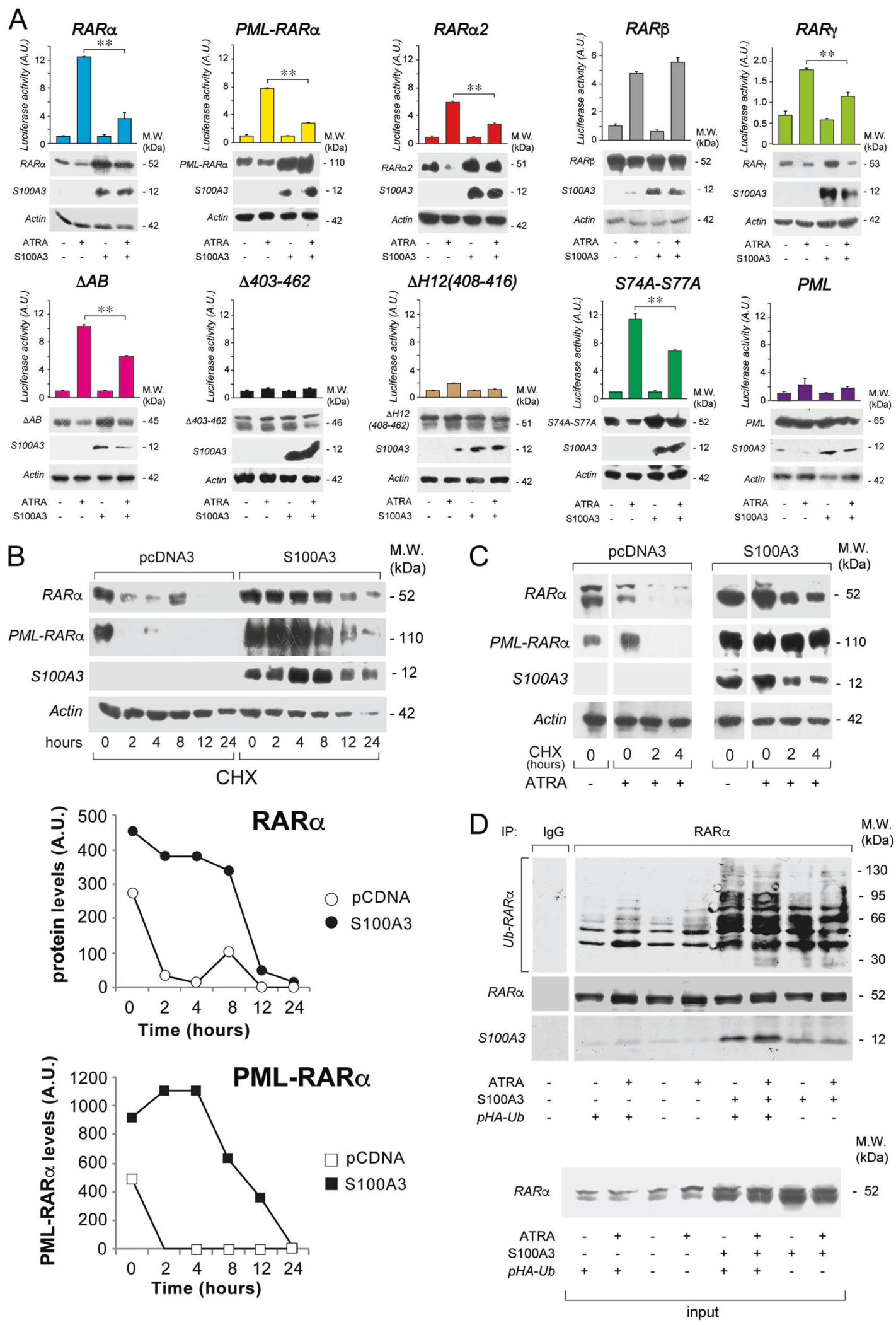

evaluated the effects of S100A3 on the ubiquitinylation of RAR $\alpha$. RAR $\alpha$, S100A3, and HA-tagged ubiquitin ( $p U b$ $H A$ ) were over-expressed in COS-7 cells exposed to vehicle

or ATRA. Cell extracts were immunoprecipitated with antiRAR $\alpha$ antibodies and blotted with antibodies recognizing poly-ubiquitinylated proteins (Fig. 3d). Regardless of 
Fig. 3 RAR $\alpha$ structural determinants of the interaction with S100A3 and effects of S100A3 on the stability and ubiquitinylation of the retinoid-receptor and the PML-RAR $\alpha$ fusion product. a $C O S-7$ cells were transiently co-transfected with an expression plasmid for the S100A3 cDNA (S100A3) or the corresponding void vector ( $p c D N A 3)$ and wild-type RAR $\alpha, \operatorname{PML}-\operatorname{RAR} \alpha, \operatorname{RAR} \alpha 2, \operatorname{RAR} \beta, \operatorname{RAR} \gamma$, the indicated RAR $\alpha$ deletion-mutants and point-mutants along with a luciferase reporter construct controlled by a retinoid responsive element $(\beta 2 R A R E-L u c)$. PML was used as an internal negative control of the experiment. Twenty-four hours following transfection, cells were treated with vehicle (DMSO) or ATRA $(1 \mu \mathrm{M})$ for a further $24 \mathrm{~h}$. Cell extracts were subjected to western blot analysis with anti-RAR $\alpha$, antiRAR $\beta$, anti-RAR $\gamma$, anti-PML (upper panels), anti-S100A3 (middle panels), and anti-actin (lower panels) antibodies. The same cell extracts were used for the measurement of luciferase activity, as illustrated by the bar graphs above the western blots. Each value is the mean \pm SD of three replicate cultures. ${ }^{*}$ Statistically significant comparison ( $p<0.01$, Student's $t$-test). b COS-7 cells were transiently cotransfected with $S 100 A 3$ or $p c D N A 3$ and wild-type RAR $\alpha$ or PMLRAR $\alpha$. Upper: twenty-four hours following transfection, cells were split and treated with cycloheximide $(\mathrm{CHX}, 10 \mu \mathrm{g} / \mathrm{ml})$ for the indicated amounts of time. Lower: the graphs indicate the results obtained following densitometric analysis of the western blot signals obtained for RAR $\alpha$ and PML-RAR $\alpha$. Densitometric analysis was performed with the Progenesis software (Nonlinear Dynamics Co.). c COS-7 cells were transfected as in (b). Twenty-four hours following transfection cells were split and treated with ATRA $(1 \mu \mathrm{M})$ for another $24 \mathrm{~h}$. Subsequently cells were exposed to CHX $(10 \mu \mathrm{g} / \mathrm{ml})$ for the indicated amounts of time. Cell extracts were subjected to western blot analysis with anti-RAR $\alpha$, anti-S100A3, and anti-actin antibodies, as indicated. Each line shows cropped lanes of the same gel, hence the results can be compared across the lanes, as they were obtained with the same exposure time. d COS-7 cells were transiently co-transfected with $S 100 A 3$ or $p c D N A 3$ and wild-type RAR $\alpha$ in the presence/absence of an HA-tagged ubiquitin expression vector $(p H A-U b)$. Twenty-four hours following transfection, cells were treated with vehicle (DMSO) or ATRA $(1 \mu \mathrm{M})$ for $1 \mathrm{~h}$. Cell extracts were immunoprecipitated with an anti-RAR $\alpha$ mouse monoclonal antibody (IP: RAR $\alpha$ ) or with nonspecific immuno-globulins G (IP: IgG) and subjected to western blot analysis with an anti-ubiquitin (upper) and anti-RAR $\alpha$ rabbit polyclonal (lower) antibodies. $U b-R A R \alpha=$ poly-ubiquitinylated RAR $\alpha$. M. $\mathrm{W} .=$ molecular weights of the indicated proteins

ATRA treatment, which stimulates the process [39], S100A3 increases RAR $\alpha$ polyubiquitinylation and the effect is magnified by $p U b-H A$. This suggests that S100A3/ RAR $\alpha$ interaction inhibits constitutive and ATRAdependent degradation of the retinoid-receptor by the proteasome.

\section{The I396 residue of RARa is critical for the interaction with S100A3}

Constitutive binding to RAR $\alpha /$ PML-RAR $\alpha$, reduction of the binding by ATRA and inhibition of RAR $\alpha /$ PML-RAR $\alpha$ transcriptional activity suggest that S100A3 is a potential nuclear-receptor co-repressor. In addition, S100A3 contains a LKELLQKEL sequence (Supplementary Fig. 6), which is similar to the core alpha-helical-box (LXXI/HIXXXIL) of co-repressors [40].
The $\mathrm{I} 396$ residue is located in proximity to the RAR $\alpha$ region involved in S100A3 binding (Supplementary Fig. 4) and the RAR $\alpha$ I396E mutant (I396E) does not bind corepressors [41]. Thus, we evaluated the capacity of $I 396 E$ to bind S100A3, in the COS-7 model. Unlike RAR $\alpha, I 396 E$ is not co-immunoprecipitated by anti-S100A3 antibodies (Fig. $4 a)$. Consistent with the inability of S100A3 to interact with I396E, the calcium-binding protein has no effect on ATRAdependent transcriptional activity or the steady-state levels of the RAR $\alpha$-mutant (Fig. 4b). As ATRA is a pan-RAR agonist, we supported the selectivity of these effects with the RAR $\alpha$ agonist, AM580 [4]. We compared the dosedependent effects of AM580 on RAR $\alpha$ and I396E transcriptional activity (Fig. 4c, left). As for RAR $\alpha$, S100A3 reduces the luciferase activity of the retinoid-dependent RARB2-TKLuc reporter, at all AM580 concentrations. In contrast, S100A3 does not affect the AM580-dependent transcriptional activity of $I 396 E$. Transcriptional inhibition by AM580 is accompanied by RAR $\alpha$-protein stabilization, while a similar effect is not observed with I396E (Fig. 4c, right).

We also evaluated whether S100A3 competes with the $\mathrm{N}-\mathrm{CoR}$ co-repressor for RAR $\alpha$ binding and we performed co-immunoprecipitation studies in COS-7 cells overexpressing combinations of the three proteins (Fig. 4d). For these studies, we used an N-CoR fragment (aa. 16292453) containing the RAR $\alpha$-binding domains [42]. Cell extracts were immunoprecipitated with anti-N-CoR antibodies and subjected to western blot analysis for RAR $\alpha$ or S100A3. N-CoR antibodies co-immunoprecipitates RAR $\alpha$ in $N$-COR and more so in $N-C O R+R A R \alpha$ transfected cells. Overexpression of S100A3 $(N-C O R+S 100 A 3$ and $N-C O R$ $+R A R \alpha+S 100 A 3$ cells) competes for the binding of $\mathrm{N}$ COR to RAR $\alpha$. This is consistent with S100A3 and N-COR binding to the same $\mathrm{H} 12$ region of $\mathrm{RAR} \alpha$.

\section{Effects of S100A3 on the cellular responses to ATRA in breast cancer cells}

To evaluate whether modulation of S100A3 expression has any consequence on ATRA anti-tumor activity, we took a silencing approach. We designed three S100A3-targeting shRNAs (shS100A3- $a$, shS100A3-b, and shS100A3-c) and a scrambled control shRNA ( $S h S C R A M)$. The specificity of our shRNAs is supported by the results obtained in COS-7 cells over-expressing S100A3 (Supplementary Fig. 7A). We infected $S K-B R-3$ cells with $s h S 100 A 3-b$ and $s h S 100 A 3-$ $c$ lentiviruses alone or in combination, shSCRAM and the void lentivirus (VOVE) isolating the following cell populations: $\quad S 100 A 3 b / S K, \quad S 100 A 3 c / S K, \quad S 100 A 3 b+c / S K$, $S C R A M / S K$, and VOVE/SK. S100A3b/SK, S100A3c/SK, and $S 100 A 3 b+c / S K$ express lower levels of S100A3 mRNA/ protein than SCRAM/SK cells (Fig. 5a). As a consequence, 


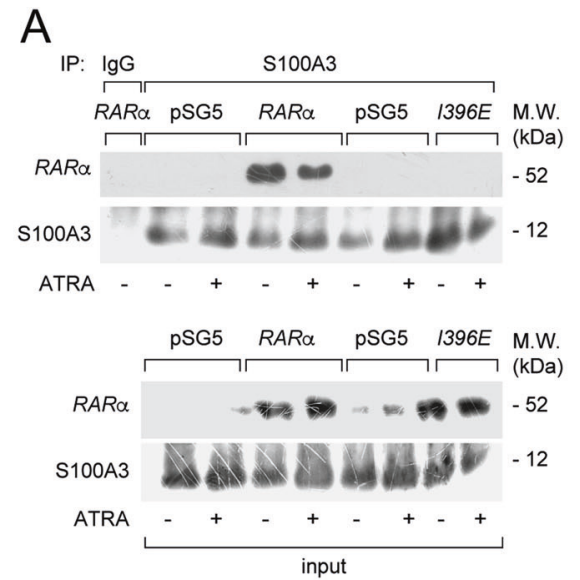

C

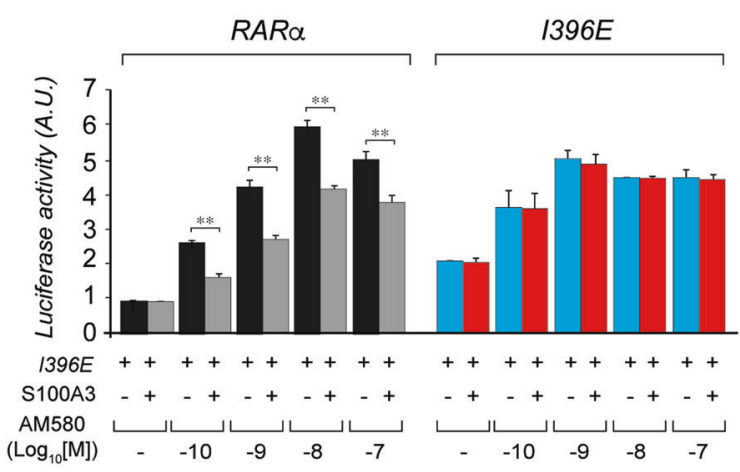

D

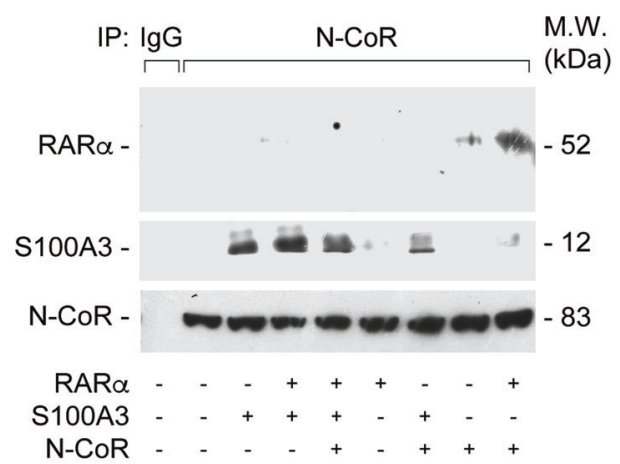

B
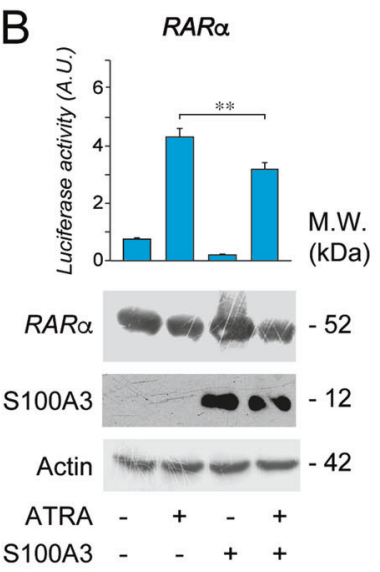

I396E

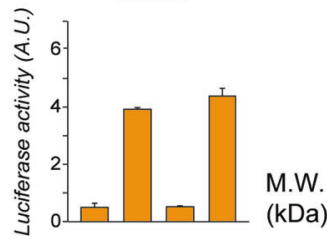

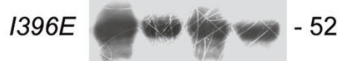

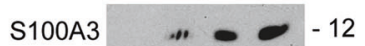

Actin $=--42$

ATRA - + - +

S100A3 - -++
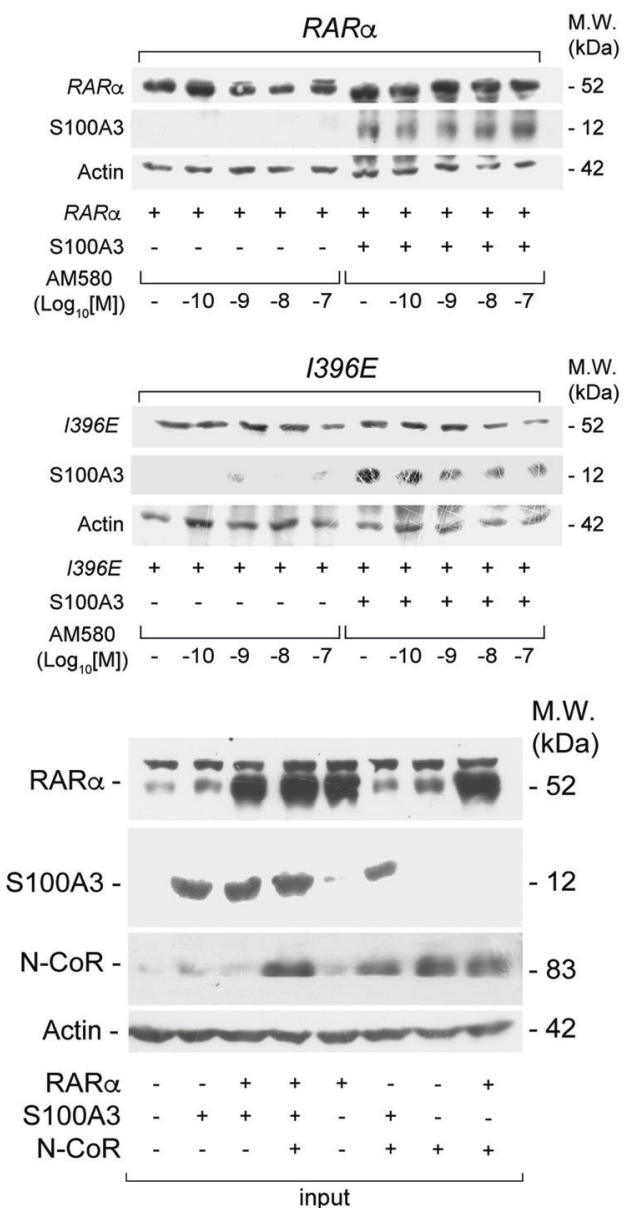

anti-RAR $\alpha$ antibodies fail to co-immunoprecipitate S100A3 from S100A3 knockdown cells (Fig. 5b). Consistent with S100A3-dependent inhibition of RAR $\alpha$ degradation, $S 100 A 3 b / S K, S 100 A 3 c / S K$, and $S 100 A 3 b+c / S K$ show lower levels of the retinoid-receptor than SCRAM/SK cells (Fig. $5 c)$. This effect is evident in basal conditions and following ATRA treatment.

We investigated the consequences of $\mathrm{S} 100 \mathrm{~A} 3$ silencing on the proliferation of $S K-B R-3$ grown under basal conditions. S100A3 knockdown exerts minor and divergent effects on the growth of $S K-B R-3$ cells, depending on the $S C R A M / S K$ or VOVE/SK control line considered (Supplementary Fig. 7B). Given the key-role played by RAR $\alpha$ in mediating ATRA anti-proliferative action in breast cancer cells, we also investigated the consequences of S100A3 silencing on ATRA-dependent growth inhibition of $S K-B R-3$ cells. Relative to $S C R A M / S K$ and VOVE/SK, S100A3a/SK, S100A3a+b/SK, S100A3b/SK, S100A3c/SK, 
Fig. 4 Interaction studies between S100A3, the RAR $\alpha$ I396E mutant and the co-repressor N-COR. a COS-7 cells were co-transfected with equal amounts of wild-type RAR $\alpha, I 396 E$, and S100A3 expression plasmids, as indicated. The negative control for the experiments is represented by cells co-transfected with the void expression plasmid (pSG5). Twenty-four hours following transfection, cells were treated with vehicle (DMSO) or ATRA $(1 \mu \mathrm{M})$ for $1 \mathrm{~h}$. At the end of the treatment, total cell extracts were immunoprecipitated with antiS100A3 mouse monoclonal antibodies (IP: S100A3). A further negative control for the immunoprecipitations is represented by the extracts of COS-7 cells co-transfected with pSG5 and the S100A3 expression plasmid which were challenged with non-specific immunoglobulins G (IP: IgG). Following normalization for the content of S100A3 in the input, the various immunoprecipitates were subjected to western blot analysis with anti-RAR $\alpha$ antibodies. All the blots were subsequently re-challenged with anti-S100A3 antibodies, as indicated. Input $=$ western blot analysis of the cell extracts before the indicated immunoprecipitation step. M.W. = molecular weights of the indicated proteins. Each immunoprecipitation is representative of at least two independent experiments providing the same type of results. b COS-7 cells were transiently co-transfected with an expression plasmid for the S100A3 cDNA (S100A3) or the corresponding void vector ( $p c D N A 3)$, wild-type RAR $\alpha$ and the RAR $\alpha$ I396E mutant (I396E) along with a luciferase reporter construct controlled by a retinoid responsive element ( $\beta 2 R A R E-L u c)$. Twenty-four hours following transfection, cells were treated with vehicle (DMSO) or ATRA $(1 \mu \mathrm{M})$ for a further $24 \mathrm{~h}$. Cell extracts were subjected to western blot analysis with anti-RAR $\alpha$ (upper panels), anti-S100A3 (middle panels) and anti-actin (lower panels) antibodies. The same cell extracts were used for the measurement of luciferase activity, as illustrated by the bar graphs above the western blots. M.W. = molecular weights of the indicated proteins. c $C O S-7$ cells were transiently transfected with the indicated expression plasmids as in (b). Twenty-four hours following transfection, cells were exposed to the indicated concentrations of the AM580 RAR $\alpha$ agonist. Left: the bar graph illustrate the levels of luciferase activity. Each value is the mean \pm SD of three replicate cultures. **Statistically significant comparison $(p<0.01$, Student's $t$-test). Right: the same extracts used for the determination of luciferase activity were subjected to western blot analysis with anti-RAR $\alpha$ (upper panels), anti-S100A3 (middle panels) and anti-actin (lower panels) antibodies. d COS-7 cells were transiently co-transfected with the indicated combinations of S100A3, RAR $\alpha$, and a N-CoR fragment (aa. 1629-2453) containing the RAR $\alpha$-binding domains (NRI and NRII). Following normalization for the content of N-COR in the input, cell extracts were immunoprecipitated with an anti-N-COR antibody (IP: N-COR) or with nonspecific immuno-globulins G (IP: IgG) and subjected to western blot analysis with anti-RAR $\alpha$, anti-S100A3, and anti-N-COR antibodies. Input $=$ western blot analysis of the cell extracts before the indicated immunoprecipitation step. M.W. = molecular weights of the indicated proteins

and $S 100 A 3 b+c / S K$ cells show decreased sensitivity to the dose-dependent anti-proliferative action of ATRA (Fig. 5dleft). We supported the involvement of RAR $\alpha$, performing experiments in AM580-treated S100A3a+b/SK, S100A3b $+c / S K$, and SCRAM/SK cells. In this case too, S100A3 silencing results in decreased sensitivity to AM580 (Fig. 5d-right).

To establish whether S100A3 silencing affects other aspects of ATRA activity, besides growth inhibition, we studied the lactogenic response [43], by measuring the cellular content of lipids [43] (Fig. 5e). While ATRA causes a dose-dependent increase of lipids in SCRAM/SK and $V O V E / S K$, this increase is suppressed in $S 100 A 3 a+b / S K$ and $S 100 A 3 b+c / S K$ cells. Thus, S100A3 knockdown reduces ATRA anti-proliferative and differentiating activity.

To evaluate whether these effects are observed in other cell-lines, we isolated lung cancer $A 549$ cells infected with VOVE (VOVE/A549), scrambled shRNA (SCRAM/A549), shS100A3b (S100A3b/A549), and shS100A3c (S100A3c/ A549). S100A3b/A549 and S100A3c/A549 cells show the expected knockdown of the S100A3 protein (Fig. 5f). As observed in SK-BR-3 cells, S100A3 knockdown exerts minor and divergent effects on the basal growth of A549 cells, depending on the shRNA considered (Supplementary Fig. 7C). Noticeably, silencing of S100A3 in S100A3b/ A549 and S100A3c/A549 cells decreases the antiproliferative action of ATRA significantly and consistently (Fig. 5g). This is accompanied by lower levels of RAR $\alpha$ than VOVE/A549 and SCRAM/A549 controls (Fig. $5 f)$.

\section{S100A3 controls basal and ATRA-dependent differentiation/proliferation of PML-RARa ${ }^{+}$NB4 cells}

S100A3 interacts not only with RAR $\alpha$ but also with the APL-specific PML-RAR $\alpha$ oncogenic protein. Thus, we evaluated the functional consequences of S100A3 silencing in PML-RAR $\alpha^{+}$and APL-derived $N B 4$ cells infected with shS100A3a (S100A3a/NB4), shS100A3c (S100A3c/NB4), shS100A3a+shS100A3c (S100A3a+c/NB4), shSCRAM (SCRAM/NB4), and VOVE (VOVE/NB4) (Fig. 6a). Unlike SCRAM/NB4, S100A3a/NB4, S100A3c/NB4, and S100A3a $+c / N B 4$ cells do not express detectable amounts of S100A3 and show decreased levels of RAR $\alpha$ and PML-RAR $\alpha$ in basal conditions and more so after ATRA treatment. In addition, S100A3a/NB4, S100A3c/NB4, and S100A3a $+\mathrm{c} /$ NB4 grow more slowly than the VOVE/NB4 and SCRAM/ NB4 controls (Fig. 6b). Finally, S100A3 knockdown enhances the anti-proliferative effect of ATRA, which is opposite to what is observed in $S K-B R-3$ and $A 549$ cells.

The therapeutic action of ATRA in APL cells is consequent to a reversion of the differentiation block caused by PML-RAR $\alpha$. The phenomenon is recapitulated in NB4 cells which undergo granulocytic differentiation upon ATRA treatment $[30,31,37,44]$. The basal levels of the granulocytic differentiation marker, NBT-reducing-activity [45], are higher in S100A3a/NB4, S100A3c/NB4, and S100A3a $+c / N B 4$ cells than the SCRAM/NB4 and VOVE/NB4 controls (Fig. 6c). In addition, ATRA causes a higher increase of NBT-reducing-activity in S100A3-silenced than control cells. S100A3 knockdown results in constitutive upregulation of the other differentiation markers, CD11c (Supplementary Fig. 8A, Fig. 6c) and CD38 (Fig. 6c). At the ATRA 

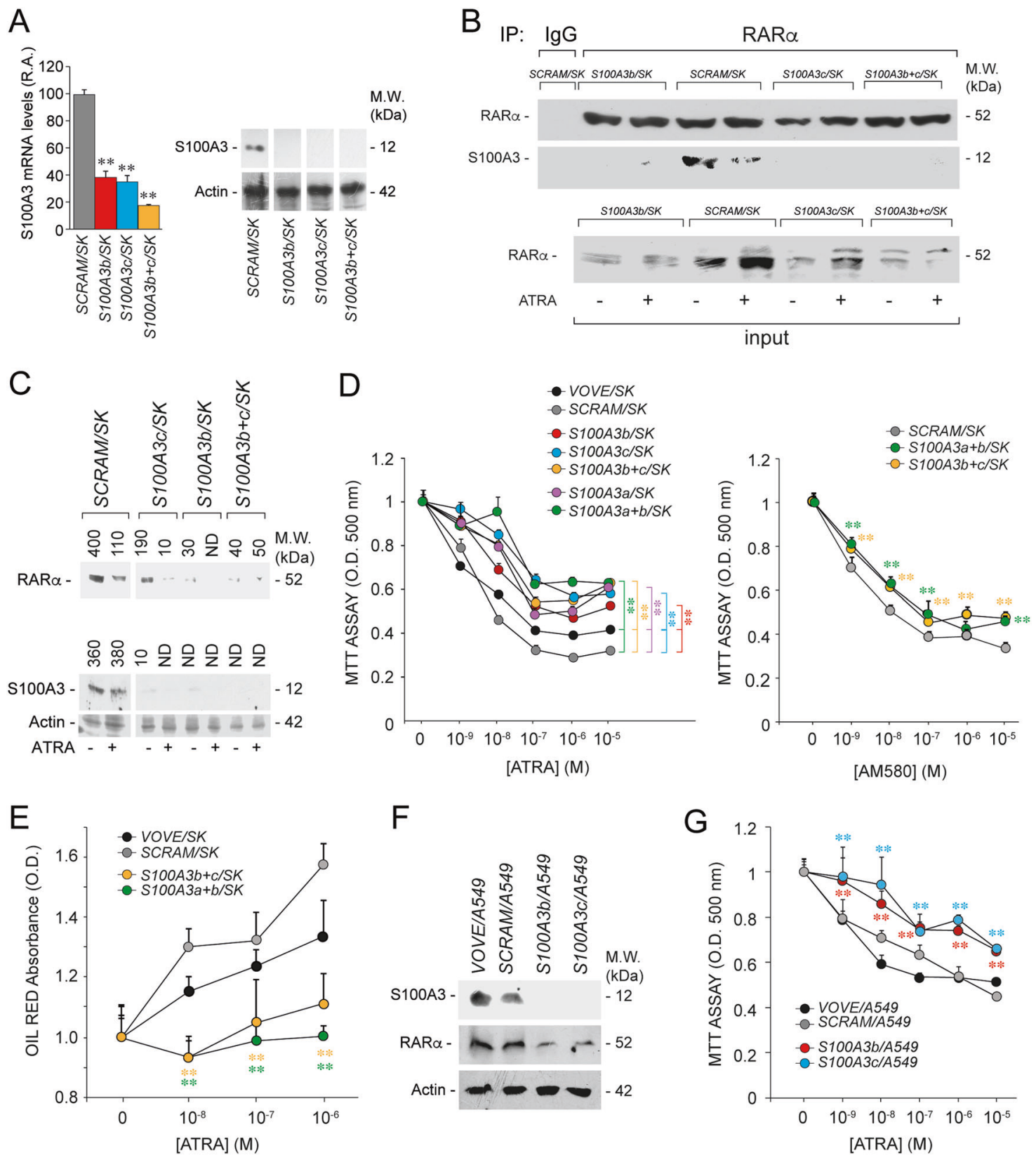

concentrations used, the expected induction of CD38 is already maximal in SCRAM/NB4, S100A3a/NB4, S100A3c/ $N B 4$, and $S 100 A 3 a+c / N B 4$ cells. In contrast, silencing of S100A3 causes a reproducible enhancement of CD11c and CD11b (another differentiation marker) induction by ATRA (Fig. 6c). As expected, CD33 is constitutively expressed in NB4 cells and its expression is left unaffected by ATRA [4]. Consistent with all this, S100A3 knockdown is associated with morphological features of granulocytic differentiation (increase in the volume of the cytoplasm and the number of granulocytic vesicles), which are already visible under basal conditions and enhanced by ATRA (Supplementary Fig. 8B).
Among the genes induced by ATRA in APL cells [32], the PU-1, $\mathrm{CEBP} \beta$, cEBPE, and STAT1 transcription factors as well as the focal adhesion protein, paxillin, are involved in granulocytic differentiation [46, 47]. ATRA induces all these proteins in $S C R A M / N B 4$ cells and this induction is magnified in S100A3a/NB4, S100A3c/NB4, and S100A3a $+c / N B 4$ cells (Fig. 6d). Interestingly, S100A3 knockdown elevates the constitutive amounts of PU-1 and STAT1, which may explain the granulocytic-differentiation signs observed under basal conditions. As cEBP $\beta$ and paxillin are encoded by direct RAR target genes, we evaluated whether the increase in ATRA-dependent upregulation by S100A3 knockdown is consistent with a transcriptional effect. 
4 Fig. 5 Functional studies in breast cancer $S K-B R-3$ and lung cancer $A 549$ cells stably silenced for the S100A3 gene. a $S K-B R-3$ cells were stably infected with lentiviruses containing the following short hairpin RNAs: $s h S C R A M$, shS1OOA3b, and $s h S 100 A 3 c$ or an equimolar combination of the two lentiviral vectors shS100A3b and shS100A3c. Infected cells were selected in puromycin for 10 days obtaining the following cell populations: SCRAM/SK, S100A3b/SK, S100A3c/SK, and $S 100 A 3 b+c / S K$. Left: the bar graph illustrates the relative S100A3 mRNA content determined by RT-PCR on total RNA extracted from the indicated cell populations grown under standard conditions. Each value is the mean \pm SD of three independent cell cultures. Right: cell extracts from the indicated cell populations were subjected to western blot analysis using anti-S100A3 and anti-actin antibodies. Each line shows cropped lanes of the same gel, hence the results can be compared across the lanes, as they were obtained with the same exposure time. M.W. = molecular weights of the indicated proteins. b The indicated $S K-B R-3$ derived cell populations were treated with vehicle (DMSO) or ATRA $(1 \mu \mathrm{M})$ for $1 \mathrm{~h}$. At the end of the treatment, total cell extracts were immunoprecipitated with anti-RAR $\alpha$ mouse monoclonal antibodies (IP: RAR $\alpha$ ). The negative control for the immunoprecipitations is represented by the extracts challenged with nonspecific immuno-globulins G (IP: IgG), as indicated. Following normalization for the content of RAR $\alpha$ in the input, the immunoprecipitates were subjected to western blot analysis with anti-RAR $\alpha$ rabbit polyclonal antibodies and anti-S100A3 mouse monoclonal antibodies, as indicated. Input $=$ western blot analyses of the cell extracts before the immunoprecipitation step. M.W. = molecular weights of the indicated proteins. $\mathbf{c}$ The indicated $S K-B R-3$ derived cell populations were treated with vehicle (DMSO) or ATRA $(1 \mu \mathrm{M})$ for $24 \mathrm{~h}$. Cell extracts were subjected to western blot analysis with anti-RAR $\alpha$, anti-S100A3, and anti-actin antibodies. The number above each lane indicates the results obtained after densitometric analysis of the bands and is expressed in arbitrary units. d $S K-B R-3$ cell populations stably infected with the void lentiviral vector $(V O V E / S K)$, the scrambled negative control shRNA $(S C R A M / S K)$, the indicated S100A3-targeting shRNA lentiviral constructs and combinations thereof were treated with vehicle and increasing concentrations of ATRA (left) or the RAR $\alpha$

Hence, we determined cEBP $\beta$ and paxillin mRNA levels in vehicle and ATRA-treated SCRAM/NB4, S100A3a/NB4, $S 100 A 3 c / N B 4$ cells (Fig. 6e). The results obtained recapitulate what is observed at the protein level, demonstrating that S100A3 knockdown causes a substantial increase in ATRA-dependent induction of the two transcripts. The data support a transcriptional effect mediated by PML-RAR $\alpha$ or RAR $\alpha$ activation by the retinoid.

To confirm the results, we used a specular approach and we stably transfected S100A3 and a void vector in $N B 4$ blasts obtaining oxS100A3/NB4 and $p C D H / N B 4$ cells, respectively. S100A3 overexpression is associated with a consistent increase in the levels of both PML-RAR $\alpha$ and RAR $\alpha$ (Fig. 7a). This is accompanied by inhibition of the ATRA-dependent degradation of the two retinoid-receptors and a modest, though significant, reduction in the antiproliferative effect of ATRA at 4 and 7 days (Fig. 7b). As for the differentiation state, the basal expression levels of NBT-reducing activity, CD11b, CD11c, CD38, and CD33 in oxS100A3/NB4 and $p C D H / N B 4$ cells are similar (Fig. 7c, d). In contrast, oxS100A3/NB4 cells are characterized by reduced ATRA-dependent upregulation of NBT-reducing agoinist, AM580 (right) for 6 days. The growth of each cell population was evaluated with the use of the MTS assay. Each experimental point is the mean \pm S.E. of four independent cell cultures. The MTS absorbance values of the $S 100 A 3 b / S K, S 100 A 3 c / S K$, and $S 100 A 3 b+c /$ $S K$ cell populations exposed to all the indicated concentrations of ATRA are significantly higher than the corresponding values determined for the VOVE/SK and SCRAM/SK counterparts $(p<0.01$ according to a two-way Student's $t$-test). With the exception of $S 100 A 3 a+b / S K\left(10^{-6} \mathrm{M}\right)$, the MTS absorbance values of the S100A3a $+b / S K, S 100 A 3 b+c / S K$ cell populations exposed to all the indicated concentrations of AM580 are significantly higher than the corresponding values determined for the VOVE/SK and SCRAM/SK counterparts $(* * p<0.01$ according to a two-way Student's $t$-test). e The indicated $S K-B R$-3-derived cell populations were treated with vehicle and increasing concentrations of ATRA for 6 days. The lactogenic differentiation state was determined with the use of the OIL-RED assay. Each experimental point is the mean + S.E. of four independent cell cultures. The OIL-RED absorbance values of the $S 100 A 3 a+b / S K$ and $S 100 A 3 b+c / S K$ cell populations exposed to all the indicated concentrations of ATRA are significantly lower than the corresponding values determined for the VOVE/SK and SCRAM/SK counterparts (** $p<0.01$ according to a two-way Student's $t$-test). f $A 549$ cells were stably infected with a void lentiviral vector $(V O V E)$ or lentiviruses containing shSCRAM, shS100A3b, and $s h S 100 A 3 c$. Infected cells were selected in puromycin for 10 days obtaining the following cell populations: VOVE/A549, SCRAM/A549, S100A3b/A549, and S100A3c/ A549. Cell extracts were subjected to western blot analysis with antiRAR $\alpha$, anti-S100A3, and anti-actin antibodies. M.W. $=$ molecular weights of the indicated proteins. $\mathrm{g}$ The indicated $A 549$ derived cell populations were treated with vehicle and increasing concentrations of ATRA for 3 days. The growth of each cell populations was evaluated with the use of the MTS assay. Each experimental point is the mean \pm S.E. of four independent cell cultures. The MTS absorbance values of the $S 100 A 3 b / A 549$ and $S 100 A 3 c / A 549$ cell populations exposed to all the indicated concentrations of ATRA are significantly higher than the corresponding values determined for the VOVE/A549 and SCRAM/ $A 549$ counterparts $(* * p<0.01$ according to a two-way Student's $t$-test)

activity (Fig. 7c), CD11b, CD11c, $c E B P \beta, \quad c E B P \varepsilon$, and PAX relative to the corresponding $p C D H / N B 4$ control (Fig. 7d, e).

\section{S100A3 knockdown controls ATRA-dependent differentiation/proliferation of PML-RARa ${ }^{-}$HL-60 cells}

To establish the relevance of the cellular context and/or PML-RAR $\alpha$ expression for the different effects afforded by S100A3 silencing in NB4 and SK-BR-3/A549, we considered the $H L-60$ AML cell line. $H L-60$ cells do not express PML-RAR $\alpha$, undergo granulocytic differentiation upon exposure to ATRA [48] and contain measurable levels of S100A3, which interacts with RAR $\alpha$ (see VOVE/HL and $S C R A M / H L$ cells, Fig. 8a, b). We generated two cell populations of $H L-60$ cells stably silenced for S100A3 $(S 100 A 3 b / H L ; S 100 A 3 a+c / H L)$ and two control populations (SCRAM/HL; VOVE/HL) (Fig. 8a). As observed in NB4 cells, S100A3 silencing was associated with decreased steady-state levels of the RAR $\alpha$ protein. Unlike the NB4 counterpart, S100A3 knockdown does not affect the basal 


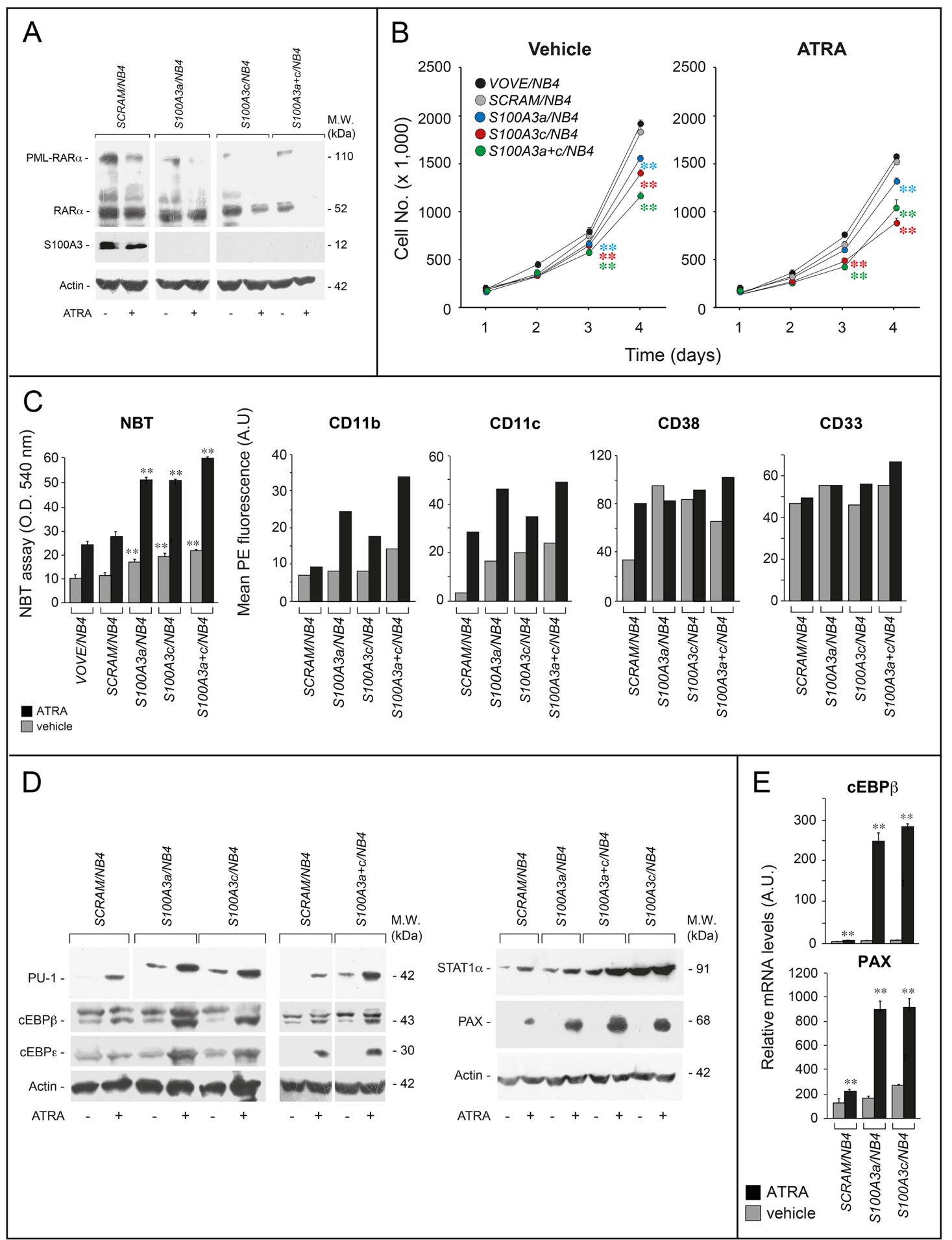

growth (Fig. 8c) differentiation state (NBT assay, CD11b, CD11c, and CD38 expression) of $H L-60$ cells (Fig. 8d, e). In contrast, S100A3 silencing enhances ATRA growthinhibitory and differentiating effects. As the results obtained in S100A3-silenced $H L-60$ and NB4 cells exposed to ATRA are substantially similar, our data indicate that the cellular context rather than PML-RAR $\alpha$ expression is the major determinant of the different effects exerted by S100A3 on
RAR $\alpha$ functional activity in myeloid leukemia relative to breast cancer and lung cancer cells.

\section{Discussion}

The study reports on the identification of novel proteins interacting with RAR $\alpha$ in breast cancer cells [3]. Among the 
Fig. 6 Functional studies in APL-derived NB4 cells stably silenced for the S100A3 gene. NB4 cells were stably infected with lentiviruses containing shSCRAM, shS100A3a, and $s h S 100 A 3 c$ or an equimolar combination of the two lentiviral vectors shS100A3a and shS100A3c. Infected cells were selected in puromycin for 10 days obtaining the following cell populations: SCRAM/NB4, S100A3a/NB4, S100A3c/ $N B 4$ and $S 100 A 3 a+c / N B 4$. a The indicated NB4 derived cell populations were treated with vehicle (DMSO) or ATRA $\left(10^{-6} \mathrm{M}\right)$ for $24 \mathrm{~h}$. Cell extracts were subjected to western blot analysis with anti-RAR $\alpha$, anti-S100A3, and anti-actin antibodies. Each line shows cropped lanes of the same gel, hence the results can be compared across the lanes, as they were obtained with the same exposure time. M.W. = molecular weights of the indicated proteins. b The indicated NB4 derived cell populations were treated with vehicle and ATRA $\left(10^{-7} \mathrm{M}\right)$ for the indicated amount of time. The growth of each cell population was evaluated by counting the number of viable cells. Each experimental point is the mean \pm S.E. of three independent cell cultures. The cell number values of the indicated shRNA expressing cell populations exposed to vehicle or ATRA are significantly lower than the corresponding values determined for the VOVE/NB4 and SCRAM/NB4 counterparts $(* * p<0.01$ according to a two-way Student's $t$-test). c The indicated NB4 derived cell populations were treated with ATRA $\left(10^{-8} \mathrm{M}\right)$ for three days. Left: cells were subjected to the NBT assay. Each experimental point is the mean \pm S.E. of three independent cell cultures. **The NBT absorbance values of the $S 100 A 3 a / N B 4$, $S 100 A 3 c / N B 4$, and $S 100 A 3 a+c / N B 4$ cell populations are significantly higher than the corresponding values determined for the $V O V E / N B 4$ and $S C R A M / N B 4$ counterparts $(p<0.01$ according to a two-way Student's $t$-test). Right: the indicated NB4 derived cell populations were treated with vehicle or ATRA $\left(10^{-8} \mathrm{M}\right)$ for 2 days. Cells were subjected to FACS analyses for the CD11b, CD11c, CD38, and CD33 surface markers, as indicated. The results are representative of two other independent experiments. $\mathbf{d}$ The indicated NB4 derived cell populations were treated with vehicle or ATRA $\left(10^{-7} \mathrm{M}\right)$ for 1 day. Cell extracts were subjected to western blot analysis for the indicated proteins using specific antibodies. Each line shows cropped lanes of the same gel, hence the results can be compared across the lanes, as they were obtained with the same exposure time. The results are representative of two other independent experiments. M.W. = molecular weights of the indicated proteins. $\mathrm{e}$ The indicated cell lines were treated with vehicle (DMSO) or ATRA $(1 \mu \mathrm{M})$ for $24 \mathrm{~h}$. Total RNA was extracted and subjected to RT-PCR with Taqman assays for the cEBP $\beta$ and paxillin. The results are the mean \pm SD of three replicates. **Significantly higher relative to the corresponding vehicle-treated sample (Student's test $p<0.01$ )

identified proteins, we focused our attention on S100A3, a member of the $\mathrm{S} 100$ family of calcium-binding proteins [49, 50]. There are no data regarding the potential involvement of S100A3 in the retinoid signal transduction pathway, although other members of the family, i.e. S100A9 and S100A10, have been implicated in ATRA-induced differentiation of APL cells [51-54]. Our data indicate that S100A3 binds to unliganded RAR $\alpha$ directly and binding is reduced by ATRA. The H12-helix located in the ligandbinding E-region of RAR $\alpha$ plays a crucial role in the interaction with S100A3. In particular, the I396 residue, laying in proximity to the H12-helix is of fundamental importance. The H12-helix and $\mathrm{I} 396$ are conserved in RAR $\beta$ and RAR $\gamma$, yet only RAR $\gamma$ interacts with S100A3. In
S100A3, a sequence similar to the one involved in the binding of co-repressor molecules to RARs (Supplementary Fig. 4) is likely to underlay the ability to compete with the $\mathrm{N}-\mathrm{COR}$ co-repressor for the binding to RAR $\alpha$. Our data are consistent with the idea that $\mathrm{S} 100 \mathrm{~A} 3$ may act as a RAR $\alpha$ corepressor and suggest that $\mathrm{S} 100 \mathrm{~A} 3$ and N-COR are unlikely to be part of the same co-repressor complex. The RAR $\alpha /$ S100A3 interaction is cell-context independent and it occurs predominantly in the cell-nucleus.

From a functional point of view, our results support the concept that the dynamic interaction with S100A3 is involved in the control of constitutive and ATRAdependent RAR $\alpha$ degradation in a cell-context independent manner. Similar effects are observed in the case of the APL-specific PML-RAR $\alpha$ fusion protein. The studies performed in S100A3 over-expressing COS-7, SK-BR-3 (MG, unpublished results), and $N B 4$ cells demonstrate an increase in the constitutive steady-state levels of both RAR $\alpha$ and PML-RAR $\alpha$, due to a decrease in the proteasome-dependent degradation of the two proteins. The inhibitory effect on RAR $\alpha$ and PML-RAR $\alpha$ degradation by S100A3 is associated with a reduction in the ligand-dependent transcriptional activity of the two retinoid-receptors. This is the opposite of what is observed upon interaction of the p38 MAP-kinase with both receptors [37]. In fact, binding of p38 MAP-kinase to RAR $\alpha$ and PML-RAR $\alpha$ causes an increase in the degradation and a decrease in the transcriptional activity of the two receptors. The above observations indicate that proteasome-dependent degradation is a crucial determinant of RAR $\alpha$ and PML-RAR $\alpha$ function, although its inhibition is not necessarily associated with an increase in their transcriptional activity [37].

The control exerted by S100A3 on RAR $\alpha$ modulates the anti-tumor activity of ATRA in breast cancer $S K-B R-3$ and lung cancer $A 549$ cells. Here, S100A3 knockdown reduces the response to the anti-proliferative action of ATRA. In $S K-B R-3$ cells a similar effect is observed also as far as the retinoid differentiating activity. Induction of ATRAresistance is consistent with the primary role exerted by RAR $\alpha$ in mediating the anti-tumor action of the retinoid in breast cancer [3] and the decrease in the levels of RAR $\alpha$ afforded by S100A3 knockdown. Interestingly, opposite effects are observed in PML-RAR $\alpha^{+} N B 4$ and PML-RAR $\alpha$ - HL-60 AML cells, where S100A3 knockdown increases the ATRA-dependent anti-proliferative and differentiating responses, despite down-regulation of RAR $\alpha$. In NB4 cells, S100A3 silencing induces not only ATRA-dependent but also basal differentiation. This is consistent with PMLRAR $\alpha$ down-regulation by S100A3 silencing. Indeed, unliganded PML-RAR $\alpha$ is believed to be responsible for the differentiation arrest of the APL blast and decreased expression of the translocation product by S100A3 knockdown may at least partially release the differentiation block. 

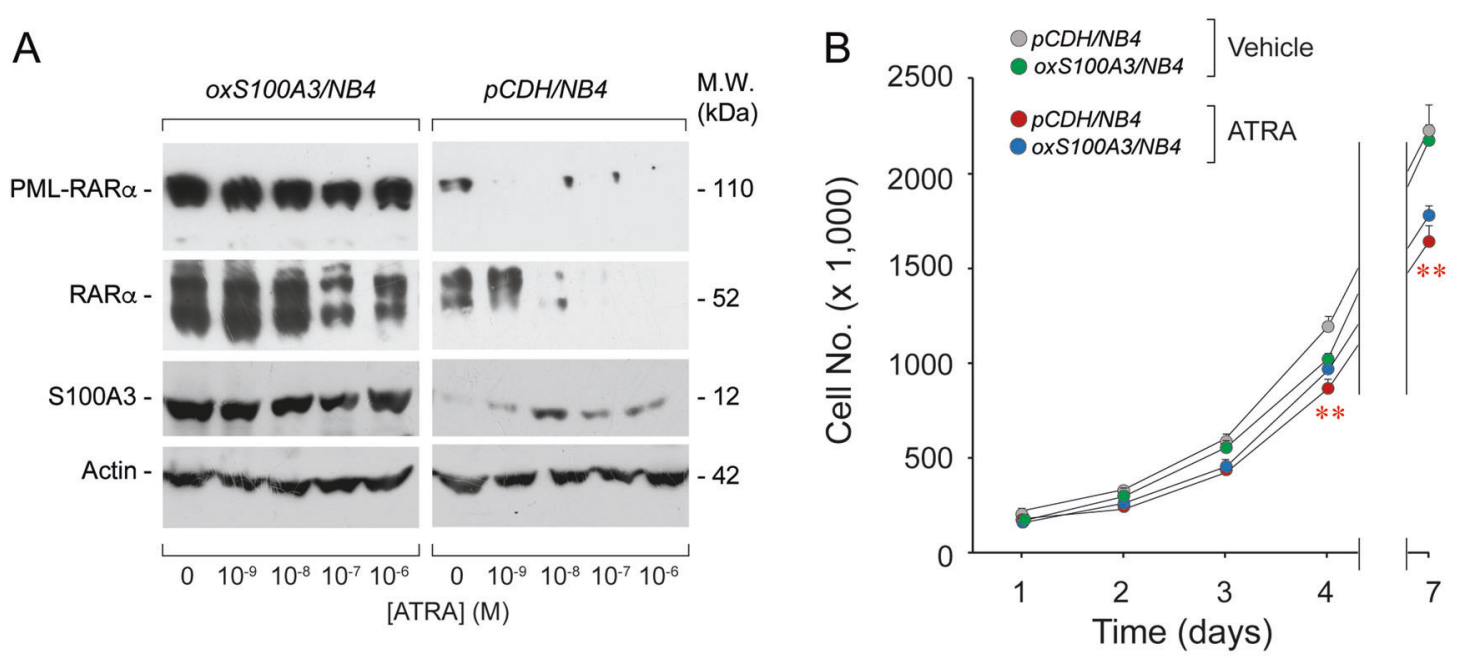

C

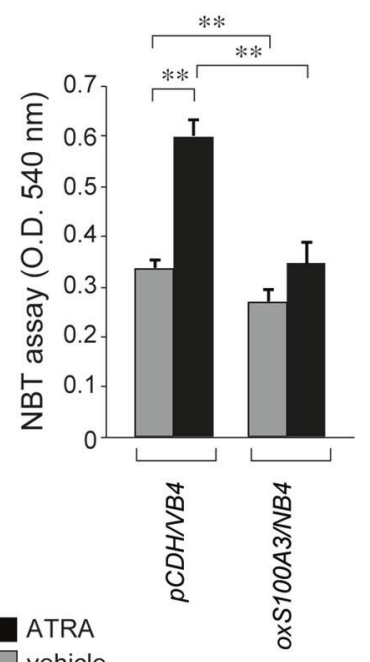

vehicle

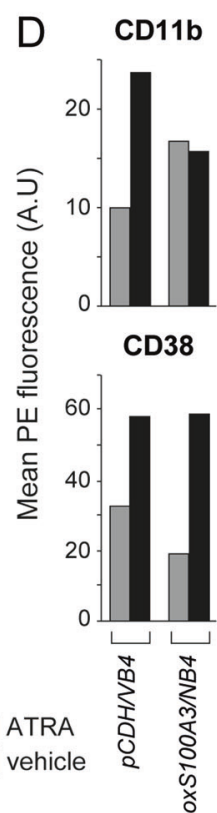

Fig. 7 Functional studies in APL-derived NB4 cells stably overexpressing the S100A3 gene. $N B 4$ cells were stably infected with a void lentivirus vector $(p C D H-C M V)$ or the same lentivirus containing the S100A3 full-length cDNA (S100A3). Transfected cells were selected in puromycin for 10 days obtaining the following cell populations: $p C D H / N B 4$ and $S 100 o x / N B 4$. a Cells were treated vehicle (DMSO) and the indicated concentrations of ATRA for $24 \mathrm{~h} . \mathrm{pCDH} /$ NB4 and S100ox/NB4 cell extracts were subjected to western blot analysis with anti-RAR $\alpha$, anti-S100A3 and anti-actin antibodies. M. $\mathrm{W} .=$ molecular weights of the indicated proteins. $\mathbf{b}$ The indicated NB4 derived cell populations were treated with vehicle and ATRA $\left(10^{-7} \mathrm{M}\right)$ for up to 7 days. The growth of each cell populations was evaluated by counting the number of viable cells. Each experimental point is the mean \pm S.E. of three independent cell cultures. $* *$ Significantly lower relative to the corresponding ATRA-treated $p C D H / N B 4$ controls

Noticeably, this is the mechanism proposed for the potentiating action of arsenic trioxide on ATRA in APL $[1,2]$. In NB4 cells, S100A3 knockdown seems to cause a larger reduction in the levels of PML-RAR $\alpha$ than RAR $\alpha$, altering
CD11c $E$

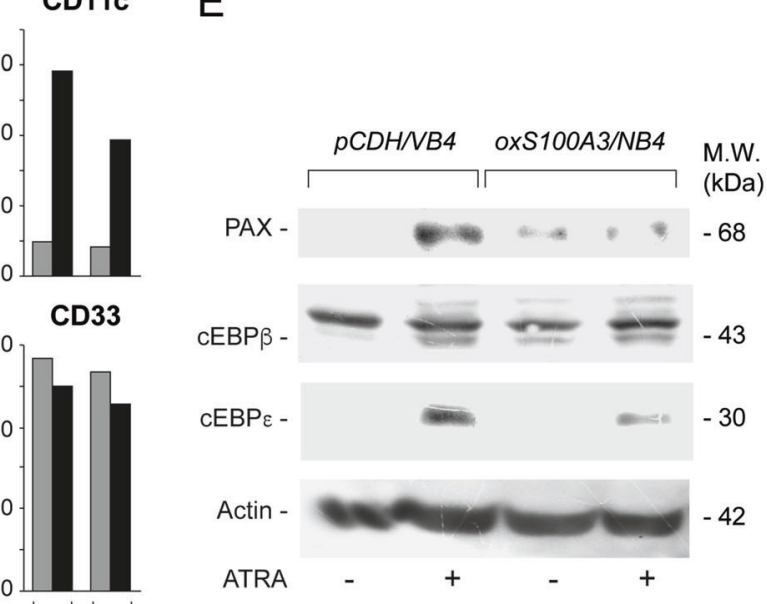

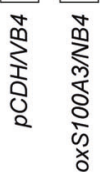

(Student's test $p<0.01$ ). c $p C D H / N B 4$ and $5100 o x / N B 4$ cells were treated with ATRA $\left(10^{-8} \mathrm{M}\right)$ for 3 days. Cells were subjected to the NBT assay. Each experimental point is the mean \pm S.E. of three independent cell cultures. ${ }^{*}$ Significantly different $(p<0.01$ according to a two-way Student's $t$-test). d $p C D H / N B 4$ and $S 100 o x / N B 4$ cells were treated with ATRA $\left(10^{-8} \mathrm{M}\right)$ for 2 days. Cells were subjected to FACS analyses for the CD11b, CD11c, CD38, and CD33 surface markers, as indicated. The results are representative of two other independent experiments. e $p C D H / N B 4$ and S100ox/NB4 cells were treated with vehicle or ATRA $\left(10^{-7} \mathrm{M}\right)$ for 1 day. Cell extracts were subjected to western blot analysis for the indicated proteins using specific antibodies. M.W. $=$ molecular weights of the indicated proteins. The results are representative of two other independent experiments

the relative abundance of the two proteins in favor of the latter one. This may release residual RAR $\alpha$ from the dominant-negative effect exerted by the oncogenic protein, potentiating the ATRA growth-inhibitory/differentiating 

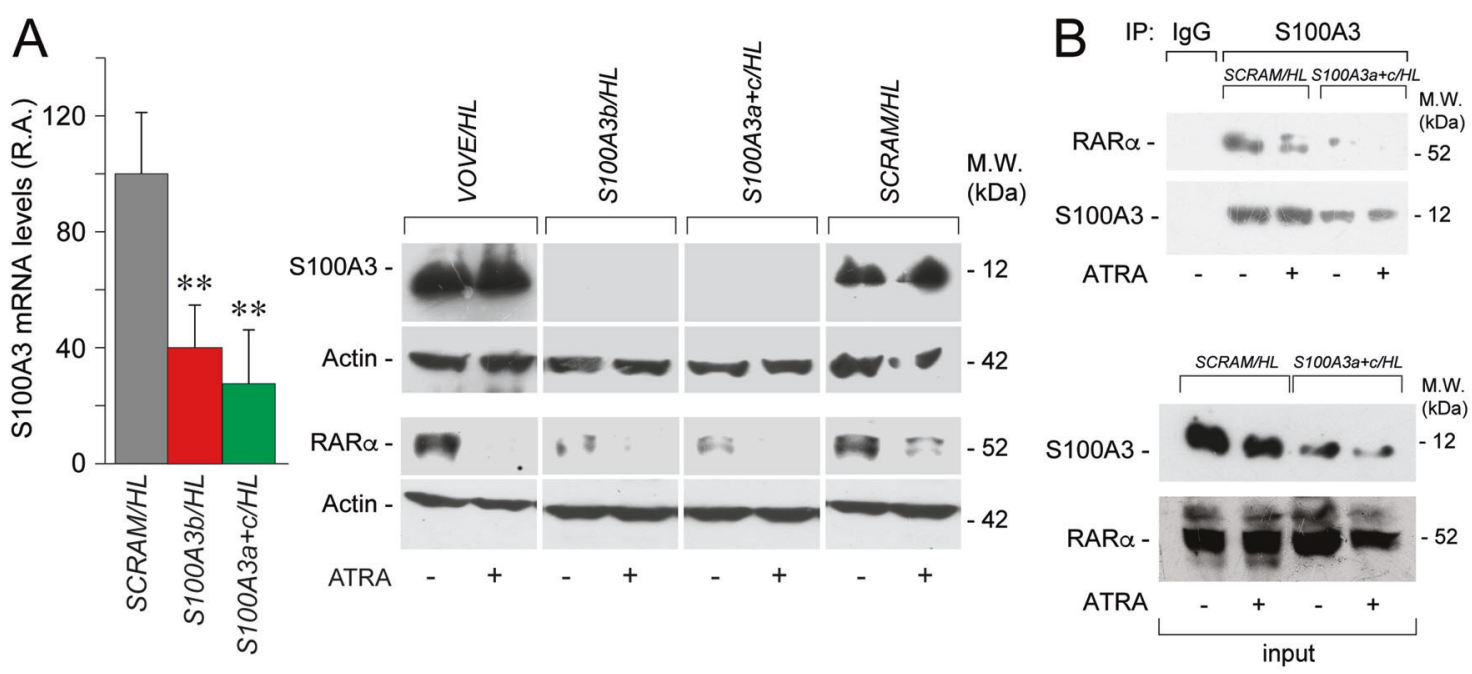

C

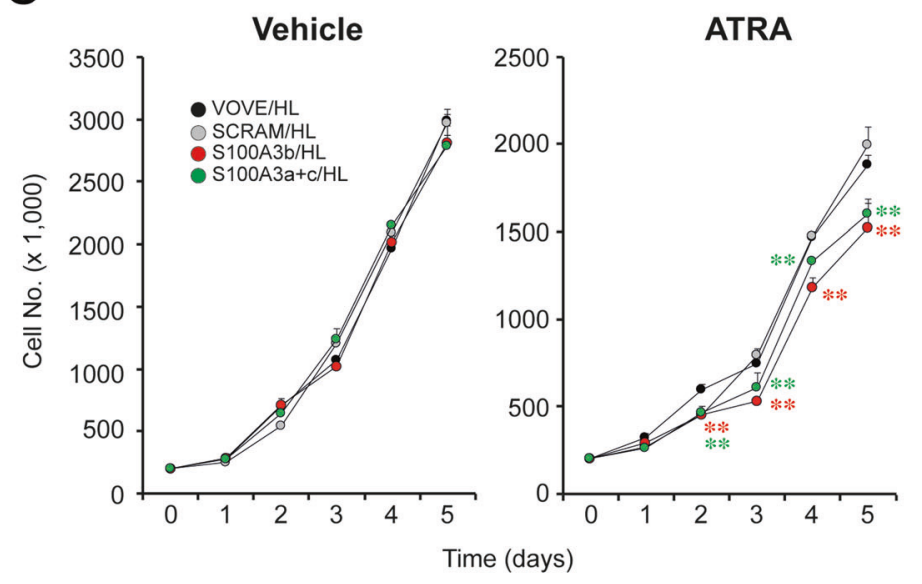

D NBT

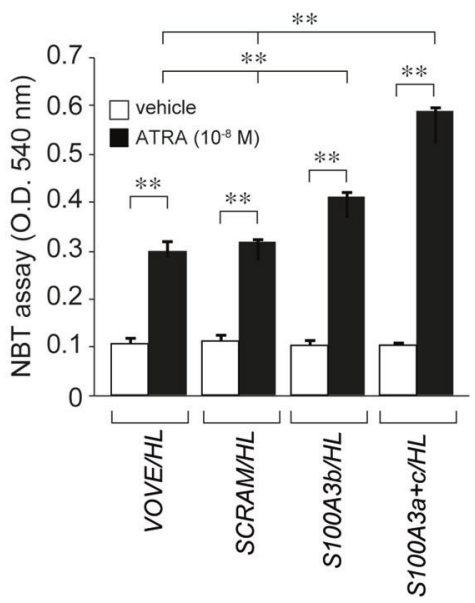

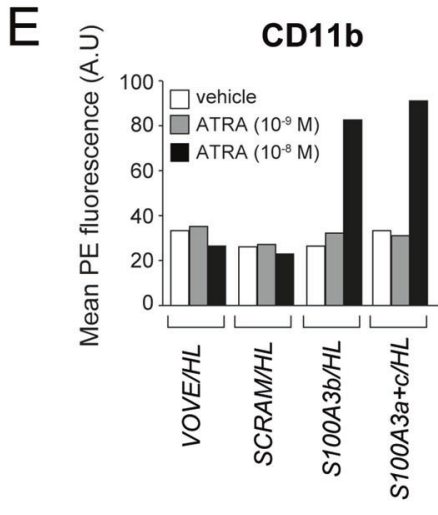

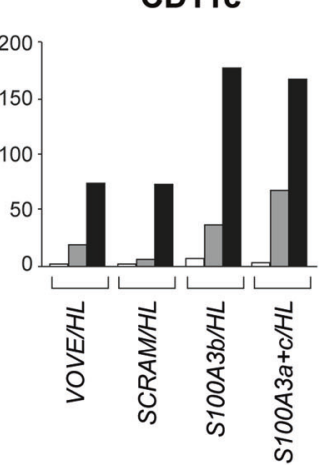

CD38

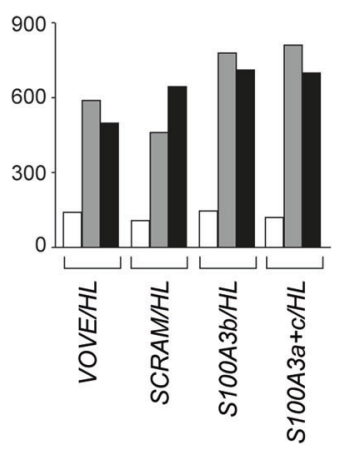

CD33

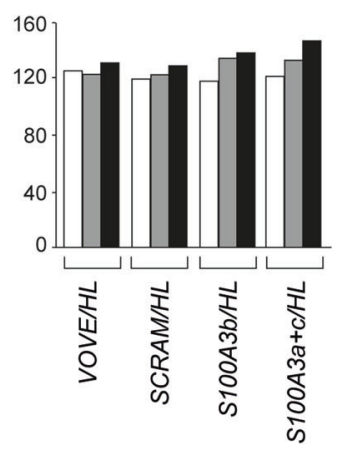

effects. However, other myeloid-cell specific mechanisms must also be involved in the enhancement of the ATRAdependent anti-proliferative effect afforded by S100A3 silencing, as indicated by the results obtained in PML-RAR $\alpha^{-}$and AML-derived $H L-60$ cells.

In conclusion, the study demonstrates that S100A3 interacts with and is involved in the proteasomal- dependent degradation of RAR $\alpha$. Our results provide new insights on the molecular mechanisms underlying the control of RAR $\alpha$ functional activity and may have practical implications. In fact, S100A3 represents a novel pharmacological target for the development of rational drug combinations aimed at potentiating the therapeutic activity of ATRA. 
Fig. 8 Functional studies in $H L-60$ cells stably silenced for the S100A3 gene. $H L-60$ cells were stably infected with lentiviruses containing shSCRAM, shS100A3b and an equimolar combination of the two lentiviral vectors $s h S 100 A 3 a+s h S 100 A 3 c$ as well as the corresponding void lentivirus (VOVE). Infected cells were selected in puromycin for 10 days obtaining the following cell populations: VOVE/HL, SCRAM/HL, S1OOA $3 b / H L$, and S100A3a+c/HL. a The indicated $H L-60$ derived cell populations were treated with vehicle (DMSO) or ATRA $\left(10^{-6} \mathrm{M}\right)$ for $24 \mathrm{~h}$. Cell extracts were subjected to western blot analysis with anti-S100A3, anti-RAR $\alpha$ and anti-actin antibodies. Each line shows cropped lanes of the same gel, hence the results can be compared across the lanes, as they were obtained with the same exposure time. M.W. = molecular weights of the indicated proteins. b $S C R A M / H L$ and $S 100 A 3 a+c / H L$ cells were treated with vehicle (DMSO) or ATRA $(1 \mu \mathrm{M})$ for $1 \mathrm{~h}$. At the end of the treatment, total cell extracts were immunoprecipitated with anti-S100A3 mouse monoclonal antibodies (IP: S100A3). The negative control for the immunoprecipitations is represented by the extracts challenged with non-specific immuno-globulins G (IP: IgG), as indicated. Following normalization for the content of S100A3 in the input, the immunoprecipitates were subjected to western blot analysis with anti-RAR $\alpha$ and anti-S100A3 antibodies, as indicated. Input $=$ western blot analyses of the cell extracts before the immunoprecipitation step. M.W. = molecular weights of the indicated proteins. c The indicated $H L-60$ derived cell populations were treated with vehicle and ATRA $\left(10^{-7} \mathrm{M}\right)$ for the indicated amount. The growth of each cell populations was evaluated by counting the number of viable cells. Each experimental point is the mean \pm S.E. of three independent cell cultures. The cell number values of the indicated shRNA expressing cell populations exposed to vehicle or ATRA are significantly lower than the corresponding values determined for the VOVE/HL and SCRAM/HL counterparts $\left({ }^{*} p<0.01\right.$ according to a two-way Student's $t$-test). d The indicated $H L-60$ derived cell populations were treated with ATRA $\left(10^{-8} \mathrm{M}\right)$ for 5 days. Cells were subjected to the NBT assay. Each experimental point is the mean \pm S.E. of three independent cell cultures. **Significantly higher $(p<0.01$ according to a two-way Student's $t$-test). e The indicated $H L-60$ derived cell populations were treated with vehicle or ATRA $\left(10^{-8} \mathrm{M}\right.$ and $\left.10^{-9} \mathrm{M}\right)$ for 2 days. Cells were subjected to FACS analyses for the CD11b, CD11c, CD38, and CD33 surface markers, as indicated. The results are representative of two other independent experiments

\section{Materials and methods}

\section{Interactomic studies}

The proteomics data were deposited in the ProteomeXchange Consortium via the PRIDE partner repository with the dataset identifier PXD00876 and further methodological details are available in Supplementary Methods.

\section{Cells and infection procedures}

The source of the cell lines and the infection procedures are described in Supplementary Methods. We generated $S K$ $B R-3, A 549, H L-60$, and NB4 cell populations silenced for S100A3 with lentiviral vectors (pGREENpuro, System Biosciences) containing the shRNA. To isolate NB4 populations over-expressing S100A3, cells were infected with $p C D H-C M V$ lentiviral vectors (System Biosciences) containing the human S100A3 cDNA. To this purpose, S100A3 was inserted in the XbaI and NotI sites of $p C D H$ CMV.

\section{Transient overexpression and transactivation studies in COS-7 cells}

COS-7 cells were transiently co-transfected with an expression plasmid for the S100A3 cDNA (S100A3) or the corresponding void vector ( $p c D N A 3)$ in the presence of pSG5 plasmids containing $\operatorname{RAR} \alpha, \operatorname{PML}-\operatorname{RAR} \alpha, \operatorname{RAR} \alpha 2$, PML or the RAR $\alpha$ point as well as deletion-mutants described in Supplementary Figure 4. The methodologies used are as described [32].

\section{Immunoprecipitation, far-western, GST pull-down assays, FACS analysis, immunoprecipitation, and western blot analyses}

Immunoprecipitation, far-western, and GST pull-down assays were performed in COS-7 cells using already described approaches and methodologies [32]. Further details are available in Supplementary Methods. CD11b, CD11c, CD38, and CD33 markers were determined with a fluorescence activated cell sorter (FACS, Becton and Dickinson) [29, 37]. Western blot analyses were performed as previously described [29, 32, 37]. Agarose beads coupled to anti-HA antibodies were from Sigma (A2095).

Acknowledgements Grants from the Associazione Italiana per la Ricerca contro il Cancro (AIRC) and the Fondazione Italo Monzino to Enrico Garattini were fundamental for the completion of this work. We would like to acknowledge the help of Mr. Alessandro Soave for the artwork.

Author contributions MG and MT supervised all the phases of the work and wrote the manuscript and contributed to the design and conduction of the study; GP and AZ performed the experimental work involving the use of cell lines; MK, AZ, GP, AA, and ML performed some of the experimental studies involving the use of cell lines. LB and RB conducted the interactomic studies involving the use of massspectrometry. MB and MF performed all the computational work; CRE participated in the design and conduction of some of the experimental work; EG designed and supervised the entire study and wrote the manuscript.

\section{Compliance with ethical standards}

Conflict of interest The authors declare that they have no conflict of interest.

Open Access This article is licensed under a Creative Commons Attribution 4.0 International License, which permits use, sharing, adaptation, distribution and reproduction in any medium or format, as long as you give appropriate credit to the original author(s) and the source, provide a link to the Creative Commons license, and indicate if changes were made. The images or other third party material in this 
article are included in the article's Creative Commons license, unless indicated otherwise in a credit line to the material. If material is not included in the article's Creative Commons license and your intended use is not permitted by statutory regulation or exceeds the permitted use, you will need to obtain permission directly from the copyright holder. To view a copy of this license, visit http://creativecommons. org/licenses/by/4.0/.

\section{References}

1. de The H. Differentiation therapy revisited. Nat Rev Cancer. 2018;18:117-27.

2. de The H, Pandolfi PP, Chen Z. Acute promyelocytic leukemia: a paradigm for oncoprotein-targeted cure. Cancer Cell. 2017;32:552-60.

3. Centritto F, Paroni G, Bolis M, Garattini SK, Kurosaki M, Barzago MM, et al. Cellular and molecular determinants of all-trans retinoic acid sensitivity in breast cancer: luminal phenotype and RAR $\alpha$ expression. EMBO Mol Med. 2015;7:950-72.

4. Gianni M, Li Calzi M, Terao M, Guiso G, Caccia S, Barbui T, et al. AM580, a stable benzoic derivative of retinoic acid, has powerful and selective cyto-differentiating effects on acute promyelocytic leukemia cells. Blood. 1996;87:1520-31.

5. Bolis M, Garattini E, Paroni G, Zanetti A, Kurosaki M, Castrignano $\mathrm{T}$, et al. Network-guided modelling allows tumor-type independent prediction of sensitivity to all-trans retinoic acid. Ann Oncol. 2016;28:611-21.

6. Chambon P. A decade of molecular biology of retinoic acid receptors. FASEB J. 1996;10:940-54.

7. Germain P, Chambon P, Eichele G, Evans RM, Lazar MA, Leid $\mathrm{M}$, et al. International union of pharmacology. LXIII. Retinoid X receptors. Pharmacol Rev. 2006;58:760-72.

8. Germain P, Chambon P, Eichele G, Evans RM, Lazar MA, Leid $\mathrm{M}$, et al. International union of pharmacology. LX. Retinoic acid receptors. Pharmacol Rev. 2006;58:712-25.

9. Benbrook DM, Chambon P, Rochette-Egly C, Asson-Batres MA. History of retinoic acid receptors. Subcell Biochem. 2014;70:120.

10. Mark M, Ghyselinck NB, Chambon P. Function of retinoid nuclear receptors: lessons from genetic and pharmacological dissections of the retinoic acid signaling pathway during mouse embryogenesis. Annu Rev Pharmacol Toxicol. 2006;46:451-80.

11. Lalevee S, Ferry C, Rochette-Egly C. Phosphorylation control of nuclear receptors. Methods Mol Biol. 2010;647:251-66.

12. Zhu J, Gianni M, Kopf E, Honore N, Chelbi-Alix M, Koken M, et al. Retinoic acid induces proteasome-dependent degradation of retinoic acid receptor alpha $(\mathrm{RAR} \alpha)$ and oncogenic RAR $\alpha$ fusion proteins. Proc Natl Acad Sci USA. 1999;96:14807-12.

13. Sahin U, Lallemand-Breitenbach V, de The H. PML nuclear bodies: regulation, function and therapeutic perspectives. J Pathol. 2014;234:289-91.

14. Bolis M, Garattini E, Paroni G, Zanetti A, Kurosaki M, Castrignano $\mathrm{T}$, et al. Network-guided modeling allows tumor-type independent prediction of sensitivity to all-trans-retinoic acid. Ann Oncol. 2017;28:611-21.

15. Hoedt E, Chaoui K, Huvent I, Mariller C, Monsarrat B, BurletSchiltz O, et al. SILAC-based proteomic profiling of the human MDA-MB-231 metastatic breast cancer cell line in response to the two antitumoral lactoferrin isoforms: the secreted lactoferrin and the intracellular delta-lactoferrin. PLoS ONE. 2014;9:e104563.

16. Kani K. Quantitative proteomics using SILAC. Methods Mol Biol. 2017;1550:171-84.

17. Joo K, Kim CG, Lee MS, Moon HY, Lee SH, Kim MJ, et al. CCDC41 is required for ciliary vesicle docking to the mother centriole. Proc Natl Acad Sci USA. 2013;110:5987-92.
18. Li XP, Jiao JU, Lu LI, Zou Q, Zhu S, Zhang Y. Overexpression of ribosomal L1 domain containing 1 is associated with an aggressive phenotype and a poor prognosis in patients with prostate cancer. Oncol Lett. 2016;11:2839-44.

19. Eckert RL, Broome AM, Ruse M, Robinson N, Ryan D, Lee K. S100 proteins in the epidermis. J Invest Dermatol. 2004;123:2333.

20. Heizmann CW, Ackermann GE, Galichet A. Pathologies involving the S100 proteins and RAGE. Subcell Biochem. 2007;45:93138.

21. Hu L, Bikle DD, Oda Y. Reciprocal role of vitamin D receptor on beta-catenin regulated keratinocyte proliferation and differentiation. J Steroid Biochem Mol Biol. 2014;144(Pt A):237-41.

22. Berry DC, Noy N. Is PPAR $\beta / \delta$ a retinoid receptor? PPAR Res. 2007;2007:73256.

23. Levi L, Wang Z, Doud MK, Hazen SL, Noy N. Saturated fatty acids regulate retinoic acid signalling and suppress tumorigenesis by targeting fatty acid-binding protein 5 . Nat Commun. 2015;6:8794.

24. Schug TT, Berry DC, Shaw NS, Travis SN, Noy N. Opposing effects of retinoic acid on cell growth result from alternate activation of two different nuclear receptors. Cell. 2007;129:723-33.

25. Caccamo D, Condello S, Ferlazzo N, Curro M, Griffin M, Ientile R. Transglutaminase 2 interaction with small heat shock proteins mediate cell survival upon excitotoxic stress. Amino Acids. 2013;44:151-9.

26. Hatakeyama D, Kozawa O, Niwa M, Matsuno H, Ito H, Kato K, et al. Upregulation by retinoic acid of transforming growth factorbeta-stimulated heat shock protein 27 induction in osteoblasts: involvement of mitogen-activated protein kinases. Biochim Biophys Acta. 2002;1589:15-30.

27. Steinbach D, Pfaffendorf N, Wittig S, Gruhn B. PRAME expression is not associated with down-regulation of retinoic acid signaling in primary acute myeloid leukemia. Cancer Genet Cytogenet. 2007;177:51-54.

28. Danielpour D, Kim KY, Winokur TS, Sporn MB. Differential regulation of the expression of transforming growth factor-beta $\mathrm{s} 1$ and 2 by retinoic acid, epidermal growth factor, and dexamethasone in NRK-49F and A549 cells. J Cell Physiol. 1991;148:235-44.

29. Gianni M, Boldetti A, Guarnaccia V, Rambaldi A, Parrella E, Raska I Jr., et al. Inhibition of the peptidyl-prolyl-isomerase Pin1 enhances the responses of acute myeloid leukemia cells to retinoic acid via stabilization of RAR $\alpha$ and PML-RAR $\alpha$. Cancer Res. 2009;69:1016-26.

30. Gianni M, Kalac Y, Ponzanelli I, Rambaldi A, Terao M, Garattini E. Tyrosine kinase inhibitor STI571 potentiates the pharmacologic activity of retinoic acid in acute promyelocytic leukemia cells: effects on the degradation of RAR $\alpha$ and PML-RAR $\alpha$. Blood. 2001;97:3234-43.

31. Gianni M, Fratelli M, Bolis M, Kurosaki M, Zanetti A, Paroni G, et al. RAR $\alpha 2$ and PML-RAR similarities in the control of basal and retinoic acid induced myeloid maturation of acute myeloid leukemia cells. Oncotarget. 2017;8:37041-60.

32. Gianni M, Fratelli M, Bolis M, Kurosaki M, Zanetti A, Paroni G. et al. RAR $\alpha 2$ and PML-RAR similarities in the control of basal and retinoic acid induced myeloid maturation of acute myeloid leukemia cells. Oncotarget. 2016;8:37041-60.

33. Piskunov A, Al Tanoury Z, Rochette-Egly C. Nuclear and extranuclear effects of retinoid acid receptors: how they are interconnected. Subcell Biochem. 2014;70:103-27.

34. Gianni M, Parrella E, Raska I Jr., Gaillard E, Nigro EA, Gaudon $\mathrm{C}$, et al. P38MAPK-dependent phosphorylation and degradation of SRC-3/AIB1 and RAR $\alpha$-mediated transcription. EMBO J. 2006;25:739-51. 
35. Gaillard E, Bruck N, Brelivet Y, Bour G, Lalevee S, Bauer A, et al. Phosphorylation by PKA potentiates retinoic acid receptor alpha activity by means of increasing interaction with and phosphorylation by cyclin $\mathrm{H} / \mathrm{cdk} 7$. Proc Natl Acad Sci USA. 2006;103:9548-53.

36. Tahayato A, Lefebvre P, Formstecher P, Dautrevaux M. A protein kinase C-dependent activity modulates retinoic acid-induced transcription. Mol Endocrinol. 1993;7:1642-53.

37. Gianni M, Peviani M, Bruck N, Rambaldi A, Borleri G, Terao $\mathrm{M}$, et al. p38 $\alpha$ MAPK interacts with and inhibits RAR $\alpha$ : suppression of the kinase enhances the therapeutic activity of retinoids in acute myeloid leukemia cells. Leukemia. 2012;26:1850-61.

38. Yoshida H, Kitamura K, Tanaka K, Omura S, Miyazaki T, Hachiya T, et al. Accelerated degradation of PML-retinoic acid receptor alpha (PML-RARA) oncoprotein by all-trans-retinoic acid in acute promyelocytic leukemia: possible role of the proteasome pathway. Cancer Res. 1996;56:2945-8.

39. Carrier M, Lutzing R, Gaouar S, Rochette-Egly C. TRIM24 mediates the interaction of the retinoic acid receptor alpha with the proteasome. FEBS Lett. 2018;592:1426-33.

40. Hu X, Lazar MA. The CoRNR motif controls the recruitment of corepressors by nuclear hormone receptors. Nature. 1999;402:9396.

41. le Maire A, Teyssier C, Erb C, Grimaldi M, Alvarez S, de Lera $\mathrm{AR}$, et al. A unique secondary-structure switch controls constitutive gene repression by retinoic acid receptor. Nat Struct Mol Biol. 2010;17:801-7.

42. Soderstrom M, Vo A, Heinzel T, Lavinsky RM, Yang WM, Seto E, et al. Differential effects of nuclear receptor corepressor (N-CoR) expression levels on retinoic acid receptormediated repression support the existence of dynamically regulated corepressor complexes. Mol Endocrinol. 1997;11:682-92.

43. Paroni G, Fratelli M, Gardini G, Bassano C, Flora M, Zanetti A, et al. Synergistic antitumor activity of lapatinib and retinoids on a novel subtype of breast cancer with coamplification of ERBB2 and RARA. Oncogene. 2012;31:3431-43.
44. Garattini E, Gianni M, Terao M. Cytodifferentiation by retinoids, a novel therapeutic option in oncology: rational combinations with other therapeutic agents. Vitam Horm. 2007;75:301-54.

45. Parrella E, Gianni M, Cecconi V, Nigro E, Barzago MM, Rambaldi A, et al. Phosphodiesterase IV inhibition by piclamilast potentiates the cytodifferentiating action of retinoids in myeloid leukemia cells. Cross-talk between the cAMP and the retinoic acid signaling pathways. J Biol Chem. 2004;279:42026-40.

46. Ovcharenko A, Granot G, Shpilberg O, Raanani P. Retinoic acid induces adhesion and migration in NB4 cells through Pyk2 signaling. Leuk Res. 2013;37:956-62.

47. Luscinskas FW. FAK and PAX-illin get involved in leukocyte diapedesis. Eur J Immunol. 2012;42:296-8.

48. Breitman TR, Selonick SE, Collins SJ. Induction of differentiation of the human promyelocytic leukemia cell line (HL-60) by retinoic acid. Proc Natl Acad Sci USA. 1980;77:2936-40.

49. Kizawa K, Jinbo $Y$, Inoue $T$, Takahara H, Unno M, Heizmann $\mathrm{CW}$, et al. Human S100A3 tetramerization propagates $\mathrm{Ca}(2+) / \mathrm{Zn}$ $(2+)$ binding states. Biochim Biophys Acta. 2013;1833:1712-9.

50. Kizawa K, Takahara H, Unno M, Heizmann CW. S100 and S100 fused-type protein families in epidermal maturation with special focus on S100A3 in mammalian hair cuticles. Biochimie. 2011;93:2038-47.

51. Wu Y, Mou Z, Li J, Zhou W, Wei B, Zou L. Identification of a S100 calcium-binding protein expressed in HL-60 cells treated with all-trans retinoic acid by two-dimensional electrophoresis and mass spectrometry. Leuk Res. 2004;28:203-7.

52. Zhu Y, Zhang F, Zhang S, Deng W, Fan H, Wang H, et al. Regulatory mechanism and functional analysis of S100A9 in acute promyelocytic leukemia cells. Front Med. 2017;11:87-96.

53. Huang D, Yang Y, Sun J, Dong X, Wang J, Liu H, et al. Annexin A2-S100A10 heterotetramer is upregulated by PML/RAR $\alpha$ fusion protein and promotes plasminogen-dependent fibrinolysis and matrix invasion in acute promyelocytic leukemia. Front Med. 2017;11:410-22.

54. O'Connell PA, Madureira PA, Berman JN, Liwski RS, Waisman DM. Regulation of S100A10 by the PML-RAR- $\alpha$ oncoprotein. Blood. 2011;117:4095-105. 